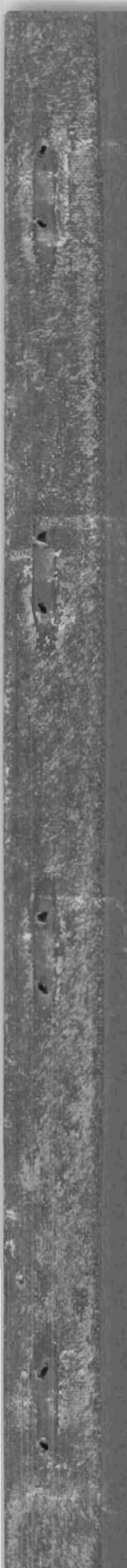

\title{
GENERATION AND BLOCKING OF EXPERIMENTAL POINTS FOR FRACTIONAL FACTORIALS
}

J. A. MAHAFFEY

J. E. SCHLOSSER

OCTOBER, 1967

\section{AEC RESEARCH \& DEVELOPMENT REPORT}

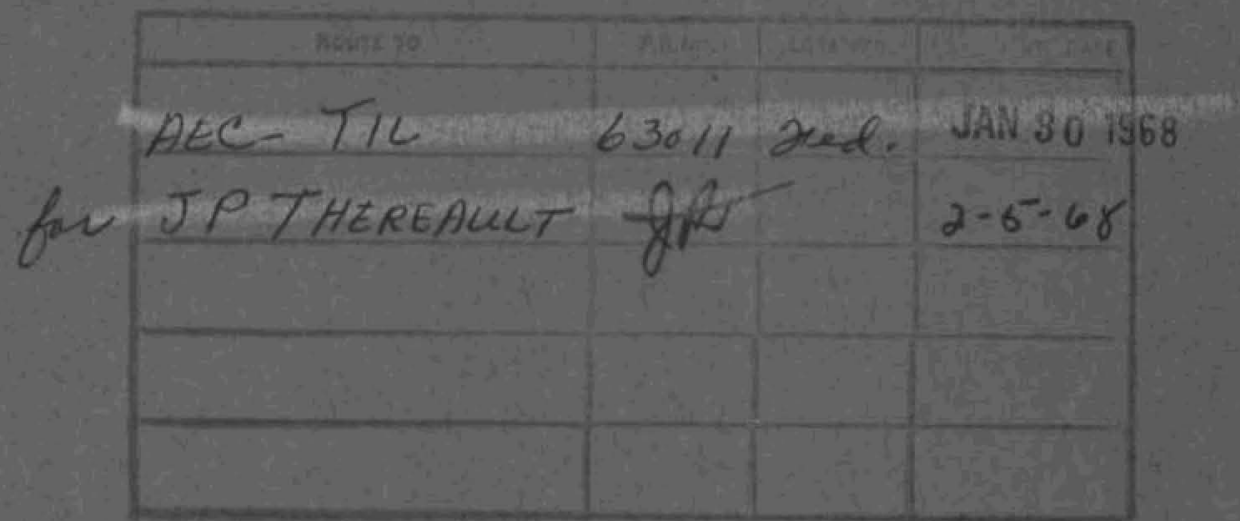




\section{LEGAL NOTICE}

This report was prepared as an ascount of Government sponsored work. Neither the United States, nor the Commission, nor any person acting on behalf of the Commission:

A. Makes any warranty or representation, expressed or implied, with respect to the occuracy, comr. pleteness, or usefulness of the information contained in this repott, or that the use af any information, opporatus, method, or process disclosed in this report may not infringe privately owned rights; or

B. Assumes any liabilities with respect to the use of, or for damages resulting from the use of any information, apparatus, method, or process disclosed in this report.

As used in the above, "person acting on behalf of the Commission" includes any employee or contractor of the Commission, or employee of such controctor, to the extent that such employee or contractor of the Commission, or employee of such contractor prepares, disseminates, or provides access to. any information pursuant to his employment or contract with the Commission, or his employment with such contractor.

\section{PACIFIC NORTHWEST LABORATORY \\ RCHLAND, WASHINGTON \\ operated by \\ BATTELLE MEMORIAL INSTITUTE:}

for the

UNITED STATES ATOMIC ENERGY COMMISSION UNDER CONTRACT AT(45-1)-1830 


\title{
33679000603094
}

1

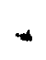

BNWL -336

UC-32, Mathematics and Computers

\author{
GENERATION AND BLOCKING OF EXPERIMENTAL \\ POINTS FOR FRACTIONAL FACTORIALS \\ By \\ J. A. Mahaffey \\ Statistics Section \\ and \\ J. E. Schlosser \\ Mathematical Analysis Section \\ Mathematics Department
}

October 1967

PACIFIC NORTHWEST LABORATORY

RICHLAND, WASHINGTON 
Printed in the United States of America Available from

Clearinghouse for Federal Scientific and Technical Information National Bureau of Standards, U.S. Department of Commerce Springfield, Virginia 22151

Price: Printed Copy $\$ 3.00 ;$ Microfiche $\$ 0.65$ 


\section{TABLE OF CONTEITS}

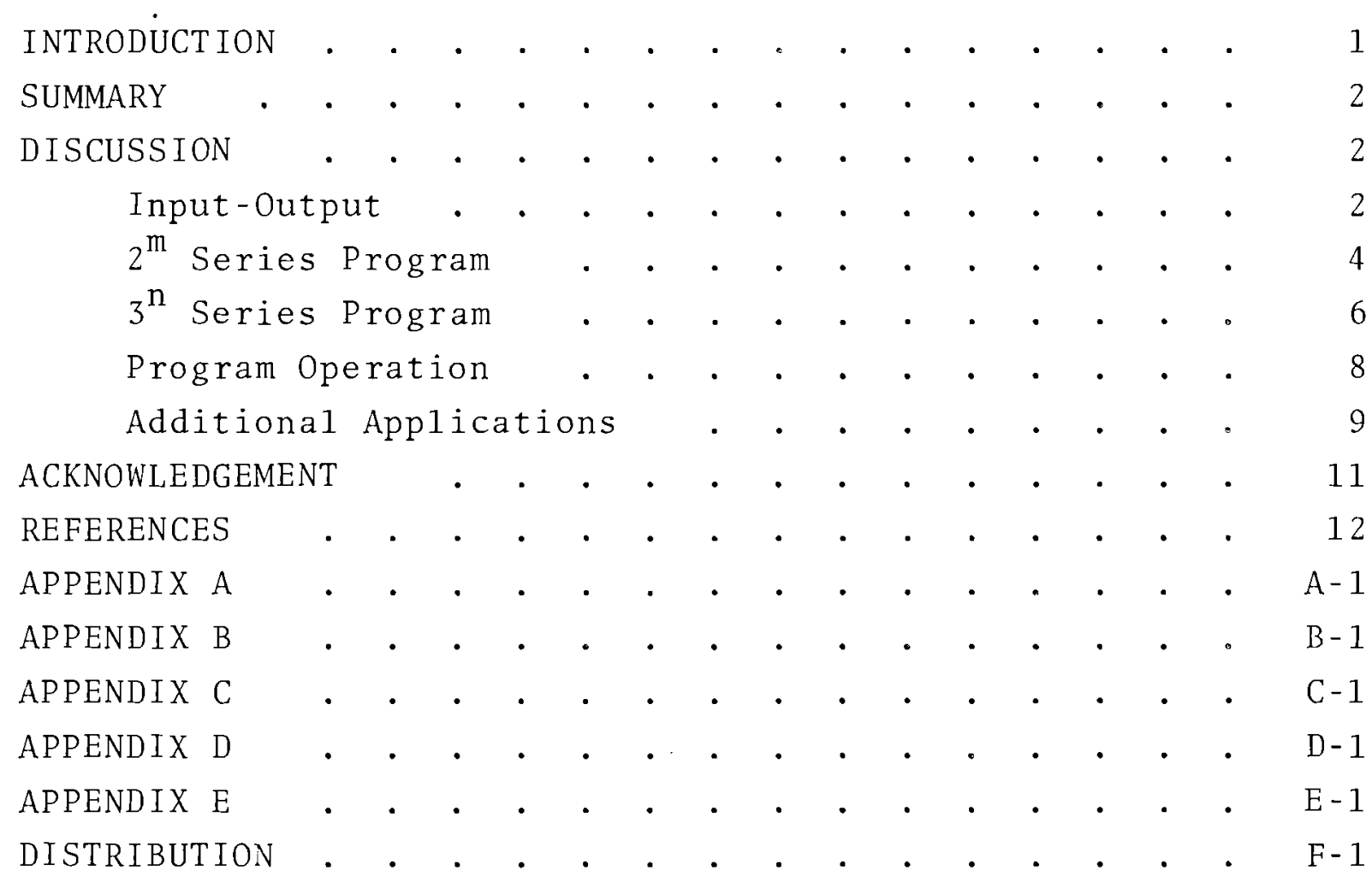




\section{GENERATION AND BLOCKIING OF EXPERIMENTAL POINTS FOR FRACTIONAL FACTORIALS \\ J. A. Mahaffey and J. E. Schlosser}

\section{INTRODUCTION}

In a factorial experiment with $t$ factors each at $k$ levels, there are $k^{t}$ possible combinations of levels of the factors. Each of these combinations will be called an experimental point, or simply a point. Various experimental designs are available for arranging these points into blocks. The purpose of this paper is to explain the use of computer programs to generate and block the points for many experimental designs using a factorial arrangement of treatments.

When the number of factors becomes large, sampling the points in a total factorial frequently becomes prohibitive in terms of cost or time. Three ways to decrease the number of points are:

- To decrease the number of factors

- To decrease the number of levels of some factors

- To sample a fractional replication of the total factorial. It will be assumed that the first two ways have been considered in the experimental planning, and that the problem still exists. Thus, the remaining alternative becomes important.

In a single replication of a $\mathrm{k}^{\mathrm{t}}$ factorial, each main effect is an average over the $k^{t-1}$ combinations of levels of the other factors, and in effect has a $k^{t-1}$-fold replication, where a smaller replication will often suffice. Similarly, each twoway interaction is an average over the other $k^{t-2}$ combinations of levels of the other factors, and so forth. If it is reasonably assumed that certain interactions are negligible, then main effects and other interactions can be estimated even though their effective replications are reduced by using a fractional factorial. This alternative has 1 imitations; foremost, the chances of misinterpretation are increased. 
For values of $m$ through 16 certain $1 / 2^{p}(p=1,2, \ldots, 8)$ fractional factorials of the $2^{\mathrm{m}}$ series have been enumerated ${ }^{(1)}$. For three level designs with values of $\mathrm{n}$ through 10 , the experimental points for particular $1 / 3^{q}$ replicates $(q=1,2,3,4,5)$ of the $3^{n}$ series are 1 isted ${ }^{(2)}$. For values of $m$ through 9 , irregular fractional replicates have been specified for the $2^{\text {m }}$ series ${ }^{(3)}$. other designs, which permit estimation of main effects but no interactions, are also available $\mathrm{e}^{(4,5)}$, as are plans that allow estimation of main effects and some two factor interactions ${ }^{(6)}$. The programs of interest here will generate the experimental points for any of these, and for other plans subject to the limitations due to computer size and time.

\section{SUMMARY}

The use of computer programs in designing experiments having factorial treatment arrangements for two, three, and four level designs is explained. The input and output are discussed and illustrated by examples, and a print-out of the programs and subroutines is included. Further possibilities for applications of these programs are suggested.

\section{DISCUSSION}

INPUT-OUTPUT

The programs are organized in the following way:

1. The input quantities are read.

2. The restrictions (resulting from the experimenter's assumption) are packed into binary words.

3. A subroutine initializes the machine language routines.

4. The admissible points are determined.

5. The experimental points are unpacked and blocked, and the output is printed.

The input consists of the restrictions and blocking restrictions. The restrictions specify which interactions are assumed to be negligible. This means that the sum of squares explained 
by the specified combination cannot be partitioned from the residual (or error) sum of squares. As a consequence, certain information that could be used in estimation and testing is not available. The blocking restrictions specify what is to be confounded with blocks.

For a prime value of $k$, there are $k$ numbers $(0,1, \ldots, k-1)$ which form a field modulo $k$. For values of $k$ that are not prime, a Galois field can be defined with elements $0,1, \ldots, k-1$. These are the characters that can be used in specifying the restrictions and blocking restrictions. These characters in a $k^{t}$ factorial, also represent the possible levels of each factor. Denote these factors as A,B,C, etc. Thus, A will have the values $0,1, \ldots, k-1$, as will each of the other factors.

Also part of a restriction is a parity indicator. This is an element of tile field or Galois field to which a specified (by the restriction) linear combination of the levels of the factors must sum to be acceptable in the design. That is, those points will be included in the design satisfying all restrictions. The restrictions are specified by puncining the proper characters in the first $k$ columns of an IBM card, and the parity indicator in column 50 .

Each blocking restriction is puncied in the first $k$ columns of a card. For example, in a $1 / 9$ replicate of a $3^{4}$ experiment with restrictions $A+2 C=0$ and $2 B+C+D=1$ and with the $A B C D$ interaction confounded with blocks, the restrictions would be entered as

$\begin{array}{rrrrrrrrr}\text { Column } & 1 & 2 & 3 & 4 & . & . & . & 50 \\ & 1 & 0 & 2 & 0 & . & . & . & 0 \\ & 0 & 2 & 1 & 1 & . & . & . & 1,\end{array}$

and the blocking restriction as

$\begin{array}{lllll}\text { Column } & 1 & 2 & 3 & 4 \\ & 1 & 1 & 1 & 1 .\end{array}$


BNWL -336

Let the experimental points be represented as

where

$$
\begin{array}{llll}
\mathrm{x}_{1} & \mathrm{x}_{2} & \mathrm{x}_{3} & \mathrm{x}_{4},
\end{array}
$$

$$
x_{i}=0,1,2 \text { for } i=1,2,3,4 .
$$

Then the points acceptable to the design simultaneously satisfy

$$
\left(1 \quad x x_{1}\right)+\left(\begin{array}{lll}
0 & x & x_{2}
\end{array}\right)+\left(2 x x_{3}\right)+\left(\begin{array}{lll}
0 & x & x_{4}
\end{array}\right)=0
$$

and

$$
\left(\begin{array}{lll}
0 & x_{1} & x_{1}
\end{array}\right)+\left(\begin{array}{lll}
2 & x_{2} & x_{2}
\end{array}\right)+\left(\begin{array}{lll}
1 & x_{3} & x_{3}
\end{array}\right)+\left(\begin{array}{lll}
1 & x_{4}
\end{array}\right)=1 .
$$

Those 27 points that satisfy the first restriction are of the form

$$
\begin{array}{ccccc}
x_{1} & x_{2} & x_{1} & x_{4}
\end{array}
$$

Of tinese, the nine which satisfy the second are of the form

$$
x_{1} \quad x_{2} \quad x_{1} \quad 2 x_{1}+x_{2}+1 .
$$

Then the blocking restriction divides these nine points into three blocks of three points each by determining whether tine quantity $x_{1}+2 x_{2}+1$ equals zero, one, or two, modulo three.

The output will consist of the restrictions, the blocking restrictions, tire number of experimental points, and the blocked experimental points. In the output the parity indicator is the left iland side of the restriction. Tine alphabetic characters on the right hand side denoting the factors are not separated by addition signs. The blocking restrictions are printed similarly, with those points whicil are in the specific block beneath them. For each block, the entire list of experimental points is scanned, and those points satisfying all blocking restrictions are printed under the appropriate headings. The last blocking card entered is printed as the first hierarchical level in the output.

\section{$\underline{2^{m} \text { SERIES PROGRAM }}$}

The essence of this program is its use of the binary computer logic. The program operates by testing the $2^{\mathrm{m}}$ points 
against the restrictions using tile logical "and" instruction. To be acceptable, a point must satisfy all restrictions. An experimental point is masked with the first restriction. If the sum of the resulting digits modulo two matches the zero or one in column 50 of the first restriction card, the point is tested against the next restriction, etc. If not, the point is destroyed. Each time a point is accepted, it is stored for further use. The program begins with the point of all zeros; rejects or accepts this point; adds one to the least significant bit; rejects or accepts, etc.; until the point of all ones is reached and tested. Thus, in a $2^{3}$ with the restriction $A+B$ $+C=1(\bmod 2)$, the four output points would be $001,010,100$, and 111 .

The program will operate with redundant restrictions. For example, the three restrictions $A+D+C+D=1(\bmod 2)$, $B+C+D+E=1(\bmod 2)$, and $A+E=0(\bmod 2)$ are redundant, since any two add to the tinird. As a consequence, the number of restrictions may be greater than $\mathrm{m}$. However, nonredundant restrictions minimize the running time of tie program. If there are $\mathrm{p}$ nonredundant restrictions in a $2^{\mathrm{m}}$ factorial, each restriction eliminates one-half of the remaining points, and $2^{\mathrm{m}-\mathrm{p}}$ experimental points are generated. It is interesting to note that if the restrictions are nonredundant, then the mean number of restrictions that a point is tested against is less than two. This is calculated in Appendix A. The restrictions should be consistent; that is, the simultaneous restrictions $A+B+C=1(\bmod 2)$ and $A+B+C=0(\bmod 2)$ should not be used. If such a combination is used, no output points will be generated because there are no points satisfying botin restrictions. After the points have been selected, a second pass in the program arranges them into $2^{s}$ blocks $\left(s=0,1,2,3,4,5 ; 2^{s}\right.$ $=1,2,4,8,16,32)$. This can be extended if more than 32 blocks are desired. The confounded effects should be consistent with the restrictions under which the points were generated. Thus, 
if the restrictions are $A+B+C+D+E=1(\bmod 2)$ and $B+C$ $+D=1(\bmod 2)$, confounding the $\mathrm{AE}$ interaction with blocks is meaningless because it is not being investigated $(A+E=0$ (mod 2)).- In this case, instead of getting output in two blocks as expected, the output would be in a single block.

$3^{n}$ SERIES PROGRAM

This program again tests the $3^{n}$ points against the restrictions and accepts only those points satisfying all restrictions. In this case, each level of each factor is represented by two bits of a single word; the three levels are represented as 00 , 01 , and 10 in the experimental points and restrictions for 0 , 1 , and 2 , respectively. The other possibility, 11 , is eliminated by "anding" the point with $1010 \ldots 10$, slifting the result one place to the right, "anding" this to the original point, and testing if the result is zero or nonzero. The net effect is to "and" together the pairs of bits representing a factor, and to test if this is zero or nonzero. If the result is zero, the original point was admissible in terms of containing no 11 combinations. If the result is nonzero, then the point contains the inadmissible character, 11. To decrease the execution time of the program, which as a consequence avoids having more than one inadmissible combination in a point at any time, the addition of unity is not always to the least significant bit. The next point is determined in the following way:

1. If a current point is admissible, then the next point to be tested for admissibility is obtained by adding unity to the least significant bit.

2. If a current point is not admissible, then the next point to be tested for admissibility is obtained by adding the nonzero word, resulting from testing the admissibility of the current point, to the current point. An illustration of this method is given in Appendix B. It should be noted that for any point containing an 11 combination, 
all the characters to the right of this combination will be zero. This is a consequence of the method of generation. Thus, only inadmissible points will be skipped, making this procedure more efficient than repetitively adding unity to the least significant bit.

After a point is determined to be admissible, it is tested against the restrictions. To do this, it is desirable to add the bits of some resultant word modulo three, and compare the result to the 0,1 , or 2 of the restriction; that is, it is desirable to multiply coefficients of proper terms in the restriction by the corresponding bits of an experimental point and have tine following table summarize the possible results.

\begin{tabular}{l|lcl} 
& 00 & 01 & 10 \\
\hline 00 & 00 & 00 & 00 \\
01 & 00 & 01 or 10 & 11 \\
10 & 00 & 11 & 01 or 10
\end{tabular}

If an "anding" is executed between the restriction and the current point, the following table would summarize the possible operations .

\begin{tabular}{c|lll} 
"and" & 00 & 01 & 10 \\
\hline 00 & 00 & 00 & 00 \\
01 & 00 & 01 & 00 \\
10 & 00 & 00 & 10
\end{tabular}

Thus, the only combinations that do not give the desired results are 01 "and" 10 and 10 "and" 01 . This can be corrected as follows :

1. "And" pairs of bits of the point and the restriction diagonally in both directions.

2. "Or" the two results.

3. Expand each single bit to two like bits.

4. "Or" this result with the result of "anding" the point and the restriction.

This procedure is illustrated in Appendix B. 
The sum of the bits then corresponds to the sum of the proper products. If this sum modulo three matches the 0 , 1 , or 2 desired, the point is acceptable. Thus, in a $3^{2}$ with the restriction $A+2 B=0(\bmod 3)$, the output points would be determined to be 0000,0101 , and 1010, and would be printed as 00,11 , and 22 (assuming no blocking).

If the $q$ restrictions are nonredundant, then the mean number of restrictions that a point is tested against is less than 3/2. This is calculated in Appendix A. The blocking routine arranges the points into $3^{\mathrm{s}}$ blocks $\left(s=0,1,2,3,4,5 ; 3^{s}=1,3\right.$, $9,27,81,243)$.

\section{PROGRAM OPERATION}

The programs were written in FORTRAN IV and machine language for the IBM 7090 and the UNIVAC 1107 computers. For increased efficiency, binary ones and zeros, which represent restrictions and experimental points, are stored as individual bits or pairs of bits in the words of the computer. Thus, the word length of these computers establishes the basic limit of the routine at 35 variables for the $2^{\mathrm{m}}$ series and at 17 variables for the $3^{\mathrm{n}}$ series. However, because of the time required to run the program, these are not serious limitations.

When the number of variables becomes large, the time required to compute the acceptable experimental points for the $2^{m}$ series is the dominant time, and is $9 \times 2^{m-14}$ sec for the IBM 7090 and $1.5 \times 2^{\text {m-14 }}$ sec for the UNIVAC 1107 . Thus, 35 variables would require about 34 days on the 1107 and 200 days on the 7090. Presently, in tis program, a limit of 25 variables was arbitrarily chosen; however, this limit could easily be extended. The great difference in running times is caused by the need to determine parity of masked words (i.e., the number of one bits in the word modulo two). On the 7090 , this requires working with each individual bit in a loop requiring six machine cycles. The 1107 contains an instruction for this 
purpose which performs the masking and determines the parity in one operation. It also leaves the word unmodified, thereby eliminating the need to restore it for further testing.

For the $3^{\mathrm{n}}$ series program, a 1 imit of 15 variables, coded for the 7090 only, was arbitrarily chosen. The 1107 would not yield the same large increase in speed on the $3^{\text {n }}$ series as it did in the $2^{n}$ case because of the more complex selection technique. For a large number of variables, the time for the $3^{n}$ series is approximately $4 \times 3^{\text {n-8 }}$ sec.

A printout of the programs is given in Appendix E. ADDITIONAL APPLICATIONS

There are several further problems that can be solved using these programs. Three of interest are:

- The generation of irregular fractions

- The generation of $2^{m} 3^{n}$ designs

- The generation of $4^{\mathrm{r}}$ designs.

Irregular fractions can be generated by repeated execution of the programs. Use of irregular fraction replicates allows partial confounding of certain main effects and interactions. For example, to generate a $3 / 4$ replicate of a $2^{3}$ factoral, the program could be executed twice--once with the restriction $A+B=1(\bmod 2)$, and once with the restrictions $A+B=0(\bmod 2)$ and $A+C=1(\bmod 2)$. The $1 / 4$ fraction, for which $A+B=0(\bmod 2)$ and $A+C=0(\bmod 2)$, has been eliminated. In this case, only the three-way interaction cannot be estimated; whereas in any $1 / 2$ replicate there are at least two effects or interactions that are not capable of being estimated. The generation of such an experiment is illustrated by Example (1) of Appendix D.

The fractions of the $2^{m_{3} n}$ series can be found by combining the output of the two programs. These can be combined as suggeted 
in Reference 7, or may be combined by putting each two-level with eacin tirree-level combination obtained. To obtain designs satisfying a restriction sucin as $A+B+2 C=0(\bmod 3)$, where $A$ has two levels and $B$ and $C$ are three level factors, is not possible by using these programs. It could be programmed, but would be very time-consuming. Asymmetrical plans can le generated by use of the $3^{n}$ program as suggested in Reference 4 , but these permit only the estimation of main effects in a $2^{m_{3}}$ experiment.

The generation of experiments of the $4^{r}$ series is possible by use of tire two level program. These can be thought of as $2^{2 r}$ designs, and eacli of the $r$ four level factors can be represented by the combination of two two level factors. liere $0=00,1=01,2=10$, and $3=11$. The use of modular arithmetic is not valid since the integers modulo four are not a field (divisors of zero are present); wilereas, the integers modulo two and three do form fields. Lowever, by use of the theory of Galois Fields, the problem can be solved.

Consider tine GF $\left(2^{2}\right)$ with four elements and primitive mark $x+1$. The addition and multiplication tables for this field are

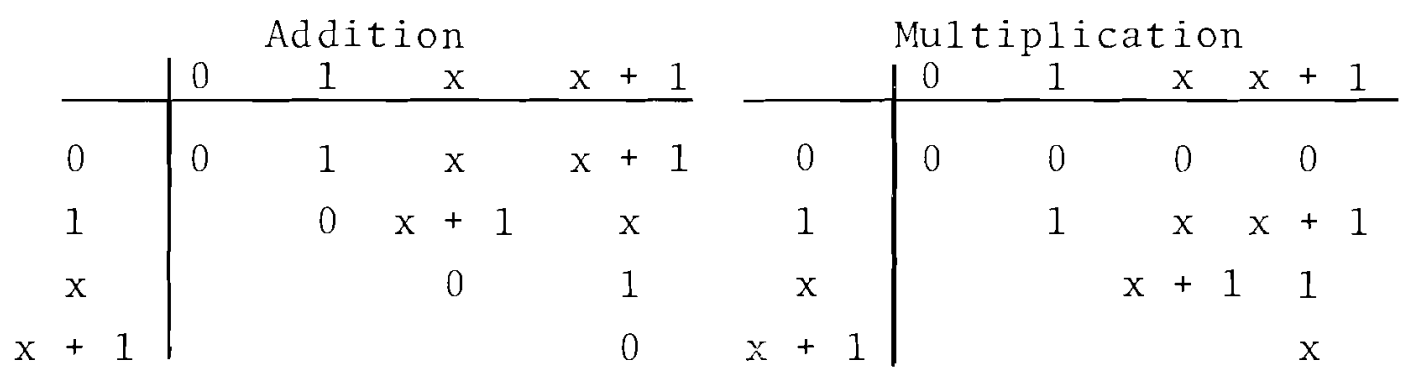

where the four elements correspond to the four levels in increasing arithmetic order. These tables are found by performing the indicated operations modulo two and modulo $x^{2}+x+1$.

Designate the four level factors as $u_{1}, u_{2}, \ldots$, and the two level factors as $V_{11}, V_{12} ; V_{21}, V_{22} ; \ldots$ wilere $V_{1 i}$ and $V_{2 i}$ 
correspond to the two characters representing $u_{i}$. A restriction in the $4^{\mathrm{r}}$ case will be represented by two restrictions in the $2^{2 r}$ situation, since one restriction with $r$ variables at four levels each gives $4^{r-1}=2^{2 r-2}$ experimental points. To find the two corresponding restrictions, it is necessary to write the $4^{r}$ restriction in terms of the elements of the Galois Field. Then transform this restriction to the $2^{\mathrm{m}}$ field by use of identities of the form

$$
u_{i}=x V_{1 i}+v_{2 i}
$$

and set the coefficients of equal powers of $x$ on both sides of the equation equal. An example of this procedure is given in Appendix C. For analysis of $4^{\mathrm{r}}$ experiments, a brief discussion is given in Reference 8. Example (3) in Appendix D illustrates the generation of points for $4^{r}$ plans.

For many experiments where the number of levels of the factors can be written as $2^{i} 3^{j}, i \geq 0, j \geq 0, i$ and $j$ integral, the experimental points can be generated by proper use of these programs. The experimental points for the designs given in References 4-6 can be easily generated by determining the independent aliases and writing these in the language of the programs. Points for designs not enumerated in these articles can thus be readily determined by use of the theory of these papers. Example (3) of Appendix $D$ was taken from Reference 6.

\section{ACKIOWLEDGEMENT}

Our thanks to Dr. W. L. ivicholson for his many comments and suggestions that were invaluable to the development of these programs. 


\section{REFERENCES}

1. Fractional Factorial Experiment Designs for Factors at Two Levels, National Bureau of Standards Applied Mathematics Series, 48, U.S. Department of Commerce, U.S. Government Printing office, Washington, D.C., 1957 .

2. Eractional Factorial Experiment Designs for Factors at Three Levels, National Bureau of Standards Applied Mathematics Series, 54, U.S. Department of Commerce, U.S. Government Printing office, Washington, D.C., 1959.

3. S. AddeIman. "Irregular Fractions of the $2^{n}$ Factorial Experiments," Technometrics vol. 3, pp. 479-496. 1960.

4. S. Addelman. "Orthogonal Main - Effect Plans for Asymmetrical Factorial Experiments," Technometrics vol. 4, pp. 21-46. 1962 .

5. R. L. Plackett, and J. P. Burman. "The Design of optimum Multifactor Experiments," Biometrika vol. 33, pp. 305-325. 1946.

6. S. Addelman. "Symmetrical and Asymmetrical Fractional Factorial plans," Technometrics vol. 4, pp. 47-58. 1962.

7. Fractional Factorial Designs for Experiments with Factors at Two and Three Levels, National Bureau of Standards Applied Mathematics Series, 58, U.S. Department of Commerce, U.S. Government Printing office, Washington, D.C., 1961.

8. W. G. Cochran, and G. M. Cox. Experimental Designs. John Wiley and Sons, Inc., New York, 1950, 2nd Edition. 
APPENDIX A 


\section{APPEWDIX A}

T0 SHOW: The mean number of restrictions that a point is tested against is less than two for the $2^{\mathrm{m}}$ program, and is less than $3 / 2$ for the $3^{\mathrm{n}}$ program.

Let

$$
\begin{aligned}
\mathrm{p}= & \text { fraction of the remaining points that is rejected by } \\
& \text { each restriction, } \\
\mathrm{x}= & \text { number of times a point is accepted preceeding its } \\
& \text { rejection. }
\end{aligned}
$$

Then

$$
P(X=k)=p(1-p)^{k} \quad k=0,1,2 \ldots .
$$

But this is the p.d.f.* of the geometric distribution and since $k$ has no upper bound, it is the limiting case for the present problem. The mean of this distribution is $1 / p$. Dut it is known that

$$
\begin{aligned}
& p=1 / 2 \text { for the } 2^{m} \text { program } \\
& p=2 / 3 \text { for the } 3^{n} \text { program. }
\end{aligned}
$$

Thus, the desired numbers, $1 / \mathrm{p}$, are 2 and $3 / 2$, respectively.

* Probability Density Function 
. 
APPENDIX B 
,

.

. 


\section{APPENDIX B}

TO SHOW: Tile operation of the $3^{\text {n }}$ program to determine if a point contains any 11 combinations and (if so) to determine the next point to be tested for admissibility.

Let the current point be

$$
\begin{array}{lllll}
10 & 00 & 01 & 11 & 00
\end{array}
$$

The following steps occur:

(1) The current point is "anded" with $1010 \ldots 10$. Thus,

$\begin{array}{ccccc}10 & 00 & 01 & 11 & 00 \\ 10 & 10 & 10 & 10 & 10 \\ & & \text { "and" } \\ 10 & 00 & 00 & 10 & 00 .\end{array}$

(2) This is shifted one place to the rigit, thus giving
01
00
00
0100

(5) This is "anded" to the original point. Thus,

$\begin{array}{ccccc}10 & 00 & 01 & 11 & 00 \\ 01 & 00 & 00 & 01 & 00 \\ & \text { "and" } & \text { gives } \\ 00 & 00 & 00 & 01 & 00 .\end{array}$

(4) This result is nonzero. The current point is inadmissible.

(5) The new current point is found by adding the final result and the current point. Thus, 


$\begin{array}{ccccc}10 & 00 & 01 & 11 & 00 \\ 00 & 00 & 00 & 01 & 00 \\ & \text { gives } & & \\ 10 & 00 & 10 & 00 & 00 .\end{array}$

This is now the current point, and can be siown to be admissible. The three inadmissible points,

$\begin{array}{lllll}10 & 00 & 01 & 11 & 01 \\ 10 & 00 & 01 & 11 & 10 \\ 10 & 00 & 01 & 11 & 11,\end{array}$

were skipped. No admissible points were skipped.

T0 SHOW: The procedure whicil allows addition of bits, modulo three, to be compared to the 0,1 , or 2 of a restriction in determining if the point satisfies the restriction.

If a point is $\begin{array}{lllllllll}1 & 2 & 1 & 2 & 0 & \text { or }\end{array}$

$$
\begin{array}{lllll}
01 & 10 & 01 & 10 & 0
\end{array}
$$

and a restriction is

$\begin{array}{lllll}10 & 10 & 01 & 01 & 10\end{array}$

$(2 A+2 B+C+D+2 E)$, then the following steps occur:

(1) The point and the restriction are "anded". Thus,

$\begin{array}{ccccc}01 & 10 & 01 & 10 & 00 \\ 10 & 10 & 01 & 01 & 10 \\ 00 & 10 & 01 & 00 & 00 .\end{array}$

(2) The two are "anded" diagonally both directions. Thus, 


$$
\begin{array}{ccccc}
01 & 01 & 01 & 10 \\
0 & 0 & 0 & 1 & 0 . \\
01 & 10 & 01 & 10 & 00 \\
10 & 10 & 01 & 01 & 10 \\
1 & & \text { gives "and" } & & \\
10 & 0 & 0 & 0 .
\end{array}
$$

(3) These two results are "ored". Thus,

$\begin{array}{ccccc}0 & 0 & 0 & 1 & 0 \\ 1 & 0 & 0 & 0 & 0 \\ & & \text { "or" } & & \\ 1 & 0 & 0 & 1 & 0 .\end{array}$

(4) Expanding, the result is

$1100 \quad 00 \quad 11 \quad 00$.

(5) This result and the result of the original

"anding" in (1) are "ored" together. Thus,

$\begin{array}{lllll}00 & 10 & 01 & 00 & 00\end{array}$

"or"

$11 \quad 00 \quad 00 \quad 11 \quad 00$

gives

$\begin{array}{lllll}11 & 10 & 01 & 11 & 00\end{array}$

(6) The sum of these bits is $6(\bmod 3)=0$. The desired result is

$$
\begin{aligned}
(2 \times 1)+(2 \times 2) & +\left(\begin{array}{lll}
1 \times 1
\end{array}\right)+\left(\begin{array}{lll}
1 \times 2
\end{array}\right) \\
+(2 \times & =9(\bmod 3)
\end{aligned}
$$


APPENDIX C 


\section{APPENDIX C}

TO SHOW: Conversion of a four level restriction to two 2-level restrictions.

If the desired four level restriction is

$$
u_{1}+x u_{2}=x+1
$$

then, by substituting,

$$
\left(x V_{11}+V_{12}\right)+x\left(x V_{21}+V_{22}\right)=x+1
$$

Setting coefficients of powers of $x$ equal, the restrictions become

$$
V_{11}+V_{21}+V_{22}=1
$$

and

$$
\mathrm{V}_{12}+\mathrm{V}_{21}=1
$$

or, in terms of the two-level programs,

$$
A+C+D=1(\bmod 2)
$$

and

$$
B+C=1(\bmod 2) \text {. }
$$

In a $4^{2}=2^{4}$ experiment, these restrictions result in the generation of the four points

$\begin{array}{llll}\text { A } & \text { B } & \text { C } & \text { D } \\ 0 & 0 & 1 & 0 \\ 0 & 1 & 0 & 1 \\ 1 & 0 & 1 & 1 \\ 1 & 1 & 0 & 0\end{array}$

or

$\begin{array}{cc}u_{1} & u_{2} \\ 0 & x \\ 1 & 1 \\ x & x+1 \\ x+1 & 0\end{array}$

These can be thought of as the points $02,11,23$, and 30 . 
APPENDIX D 


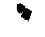

-

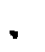

$\checkmark$ 


\section{APPEIIDIX D}

\section{EXAMPLE (1)}

Reference: (3), Table 3A, p. 492

Experiment: $3 / 4$ replicate of a $2^{6}$

Number of experimental points: 48

Computer: UNIVAC 1107

Time required: $0.87 \mathrm{sec}$

Restrictions:

$$
\begin{array}{ll}
\text { Run } 1: & A+B+C+D=0, A+B+E+F=1 \\
\text { Run 2: } & A+B+C+D=1
\end{array}
$$

Blocking restrictions: None

Comments: The same points could have been generated by the following sets of restrictions:

$$
\begin{array}{ll}
\text { Run 1: } & A+B+E+F=0, A+B+C+D=1 \\
\text { Run 2: } & A+B+E+F=1
\end{array}
$$

$$
\begin{array}{ll}
\operatorname{Run} 1: & A+B+C+D=0, A+B+E+F=1 \\
\operatorname{Run} 2: & A+B+C+D=1, A+B+E+F=1 \\
\operatorname{Run} 3: & A+B+C+D=1, A+B+E+F=0
\end{array}
$$

Further, rather than using $\mathrm{A}+\mathrm{B}+\mathrm{C}+\mathrm{D}$ and $\mathrm{A}+$ $\mathrm{B}+\mathrm{E}+\mathrm{F}, \mathrm{C}+\mathrm{D}+\mathrm{E}+\mathrm{F}$ could have been used in appropriate combination with either of the other two, or in addition to both if $C+D+E+F$ were equal to their sum.

Computer output: 


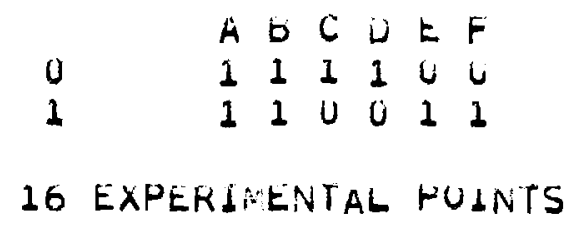

$0=$

$A B C D E F$

$\begin{array}{llllll}1 & 0 & 1 & 0 & 0 & 0\end{array}$

$0 \begin{array}{llllll}0 & 1 & 1 & 0 & 0 & 0\end{array}$

10001100

0100100

$0 \begin{array}{llllll}0 & 0 & 0 & 0 & 1 & 0\end{array}$

$\begin{array}{llllll}1 & 1 & 0 & 0 & 1 & 0\end{array}$

$\begin{array}{llllll}0 & 0 & 1 & 1 & 1 & 0\end{array}$

$\begin{array}{llllll}1 & 1 & 1 & 1 & 1 & 0\end{array}$

$\begin{array}{llllll}0 & 0 & 0 & 0 & 0 & 1\end{array}$

$\begin{array}{llllll}1 & 1 & 0 & 0 & 0 & 1\end{array}$

$\begin{array}{llllll}0 & 0 & 1 & 1 & 0 & 1\end{array}$

$\begin{array}{llllll}1 & 1 & 1 & 1 & 0 & 1\end{array}$

1001011

J $111 \cup 1$

$\begin{array}{lllllll}1 & 0 & 0 & 1 & 1 & 1\end{array}$

$0 \begin{array}{llllll}0 & 1 & 0 & 1 & 1 & 1\end{array}$

$1=$

$A \& C E E F$

TIME REQUIREU WAS .404 SECUINUS.

6 VARIADLES I KESTRLCTIONS

$$
\begin{array}{lllllll} 
& A & B & C & U & E & F \\
1 & 1 & 1 & 1 & 1 & 0 & U \\
32 & \text { EXPERIMENTAL HUINTS }
\end{array}
$$


$0=$

$\begin{array}{llllll}A & B & C & 0 & 5 & + \\ 1 & 0 & 0 & 0 & 0 & 0 \\ 0 & 1 & 0 & 0 & 0 & 0 \\ 0 & 0 & 1 & 0 & 0 & 0 \\ 1 & 1 & 1 & 0 & 0 & 0 \\ 0 & 0 & 0 & 1 & 0 & 0 \\ 1 & 1 & 0 & 1 & 0 & 0 \\ 1 & 0 & 1 & 1 & 0 & 0 \\ 0 & 1 & 1 & 1 & 0 & 0 \\ 1 & 0 & 0 & 0 & 1 & 0 \\ 0 & 1 & 0 & 0 & 1 & 0 \\ 0 & 0 & 1 & 0 & 1 & 0 \\ 1 & 1 & 1 & 0 & 1 & 0 \\ 0 & 0 & 0 & 1 & 1 & 0 \\ 1 & 1 & 0 & 1 & 1 & 0 \\ 1 & 0 & 1 & 1 & 1 & 0 \\ 0 & 1 & 1 & 1 & 1 & 0 \\ 1 & 0 & 0 & 0 & 0 & 1 \\ 0 & 1 & 0 & 0 & 0 & 1 \\ 0 & 0 & 1 & 0 & 0 & 1 \\ 1 & 1 & 1 & 0 & 0 & 1 \\ 0 & 0 & 0 & 1 & 0 & 1 \\ 1 & 1 & 0 & 1 & 0 & 1 \\ 1 & 0 & 1 & 1 & 0 & 1 \\ 0 & 1 & 1 & 1 & 0 & 1 \\ 1 & 0 & 0 & 0 & 1 & 1 \\ 0 & 1 & 0 & 0 & 1 & 1 \\ 0 & 0 & 1 & 0 & 1 & 1 \\ 1 & 1 & 1 & 0 & 1 & 1 \\ 0 & 0 & 0 & 1 & 1 & 1 \\ 1 & 1 & 0 & 1 & 1 & 1 \\ 1 & 0 & 1 & 1 & 1 & 1 \\ 0 & 1 & 1 & 1 & 1 & 1\end{array}$

$1=$

$A B C \cup E+$

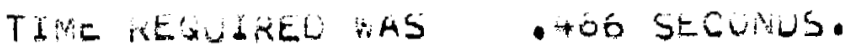

\section{EXAMPLE (2)}

Reference: (2), P1an 243.9.9, p. 35

Lxperiment: $\frac{1}{243}$ replicate of a $3^{9}$ in 9 blocks of 9 units each. Number of Experimental Points:

Computer: IBM 7090

Time Required: Approximately 12 seconds. 
Restrictions: $B+C+D+E+F+G=0$,

$$
\begin{aligned}
& A+C+D+2 E+2 F+H=0, \\
& A+B+2 D+2 E+F+I=0, \\
& A+B+2 C+E+2 F=0, \\
& A+2 B+2 C+D+F=0 .
\end{aligned}
$$

Blocking Restrictions: $\mathrm{A}+\mathrm{B}+2 \mathrm{C}, \mathrm{B}+\mathrm{C}$

Comments: The restrictions and blocking restrictions in

all of the $3^{n}$ experimental plans in Reference (2) are in bold print in the enumeration. In Reference (1), the $2^{\mathrm{m}}$ series experimental plans, the independent aliases can be picked from the list, since they are numbers $2^{0}=1,2^{1}=2$, $2^{2}=4, \ldots$.

Computer Output:

9 VARIABLES

\section{RESTRICTIONS}

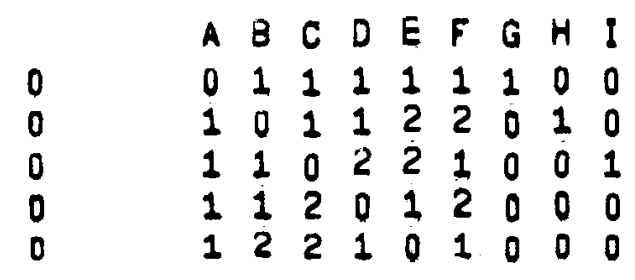

O1 EXPERIMENTAL POINTS

$0=B \quad C$

$0=A \quad B 2 C$ 


$$
1=A \quad B 2 C
$$

$$
\begin{array}{lllllllll}
A & B & C & D & E & F & G & H & 1 \\
2 & 1 & 2 & 1 & 2 & 0 & 0 & 0 & 0 \\
0 & 2 & 1 & 0 & 2 & 0 & 1 & 1 & 0 \\
1 & 0 & 0 & 2 & 2 & 0 & 2 & 2 & 0 \\
2 & 1 & 2 & 2 & 1 & 2 & 1 & 0 & 1 \\
0 & 2 & 1 & 1 & 1 & 2 & 2 & 1 & 1 \\
1 & 0 & 0 & 0 & 1 & 2 & 0 & 2 & 1 \\
2 & 1 & 2 & 0 & 0 & 1 & 2 & 0 & 2 \\
0 & 2 & 1 & 2 & 0 & 1 & 0 & 1 & 2
\end{array}
$$

$2=B 2 C$

$$
\begin{array}{lllllllll}
A & B & C & D & E & F & G & H & 1 \\
1 & 2 & 1 & 2 & 1 & 0 & 0 & 0 & 0 \\
2 & 0 & 0 & 1 & 1 & 0 & 1 & 1 & 0 \\
0 & 1 & 2 & 0 & 1 & 0 & 2 & 2 & 0 \\
1 & 2 & 1 & 0 & 0 & 2 & 1 & 0 & 1 \\
2 & 0 & 0 & 2 & 0 & 2 & 2 & 1 & 1 \\
0 & 1 & 2 & 1 & 0 & 2 & 0 & 2 & 1 \\
1 & 2 & 1 & 1 & 2 & 1 & 2 & 0 & 2 \\
2 & 0 & 0 & 0 & 2 & 1 & 0 & 1 & 2 \\
0 & 1 & 2 & 2 & 2 & 1 & 1 & 2 & 2
\end{array}
$$

$1=B C$

$0=A B 2 C$

$$
\begin{array}{lllllllll}
A & B & C & D & E & F & G & H & 1 \\
0 & 2 & 2 & 2 & 2 & 2 & 2 & 0 & 0 \\
1 & 0 & 1 & 1 & 2 & 2 & 0 & 1 & 0 \\
2 & 1 & 0 & 0 & 2 & 2 & 1 & 2 & 0 \\
0 & 2 & 2 & 0 & 1 & 1 & 0 & 0 & 1 \\
1 & 0 & 1 & 2 & 1 & 1 & 1 & 1 & 1 \\
2 & 1 & 0 & 1 & 1 & 1 & 2 & 2 & 1 \\
0 & 2 & 2 & 1 & 0 & 0 & 1 & 0 & 2 \\
1 & 0 & 1 & 0 & 0 & 0 & 2 & 1 & 2 \\
2 & 1 & 0 & 2 & 0 & 0 & 0 & 2 & 2
\end{array}
$$

$1=A B 2 C$

$$
\begin{array}{lllllllll}
A & B & C & D & E & F & G & H & ! \\
2 & 0 & 1 & 0 & 1 & 2 & 2 & 0 & 0 \\
0 & 1 & 0 & 2 & 1 & 2 & 0 & 1 & 0 \\
1 & 2 & 2 & 1 & 1 & 2 & 1 & 2 & 0 \\
2 & 0 & 1 & 1 & 0 & 1 & 0 & 0 & 1 \\
0 & 1 & 0 & 0 & 0 & 1 & 1 & 1 & 1 \\
1 & 2 & 2 & 2 & 0 & 1 & 2 & 2 & 1 \\
2 & 0 & 1 & 2 & 2 & 0 & 1 & 0 & 2 \\
0 & 1 & 0 & 1 & 2 & 0 & 2 & 1 & 2 \\
1 & 2 & 2 & 0 & 2 & 0 & 0 & 2 & 2
\end{array}
$$




\section{$2=\wedge \quad 2 \mathrm{C}$}

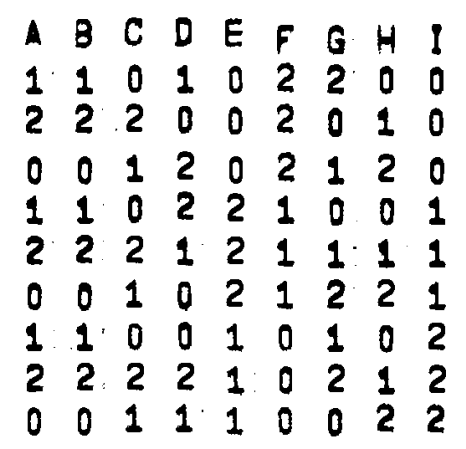

2 B C

$0=A \quad 2 \mathrm{C}$

A B DEFGHI

$\begin{array}{lllllllll}0 & 1 & 1 & 1 & 1 & 1 & 1 & 0 & 0\end{array}$

$\begin{array}{lllllllll}1 & 2 & 0 & 0 & 1 & 1 & 2 & 1 & 0\end{array}$

$\begin{array}{lllllllll}2 & 0 & 2 & 2 & 1 & 1 & 0 & 2 & 0\end{array}$

$\begin{array}{lllllllll}0 & 1 & 1 & 2 & 0 & 0 & 2 & 0 & 1\end{array}$

$\begin{array}{lllllllll}1 & 2 & 0 & 1 & 0 & 0 & 0 & 1 & 1\end{array}$

$\begin{array}{lllllllll}2 & 0 & 2 & 0 & 0 & 0 & 1 & 2 & 1\end{array}$

$\begin{array}{lllllllll}0 & 1 & 1 & 0 & 2 & 2 & 0 & 0 & 2\end{array}$

$\begin{array}{lllllllll}1 & 2 & 0 & 2 & 2 & 2 & 1 & 1 & 2 \\ 2 & 0 & 2 & 1 & 2 & 2 & 2 & 2 & 2\end{array}$

1. A $B 2 C$

$\begin{array}{lllllllll}A & B & C & D & E & F & G & H & \text { I } \\ 2 & 2 & 0 & 2 & 0 & 1 & 1 & 0 & 0\end{array}$

$\begin{array}{lllllllll}0 & 0 & 2 & 1 & 0 & 1 & 2 & 1 & 0\end{array}$

$\begin{array}{lllllllll}1 & 1 & 1 & 0 & 0 & 1 & 0 & 2 & 0\end{array}$

$\begin{array}{lllllllll}2 & 2 & 0 & 0 & 2 & 0 & 2 & 0 & 1\end{array}$

$\begin{array}{lllllllll}0 & 0 & 2 & 2 & 2 & 0 & 0 & 1 & 1\end{array}$

$\begin{array}{lllllllll}1 & 1 & 1 & 1 & 2 & 0 & 1 & 2 & 1\end{array}$

$\begin{array}{lllllllll}1 & 2 & 0 & 1 & 1 & 2 & 0 & 0 & 2\end{array}$

$\begin{array}{lllllllll}0 & 0 & 2 & 0 & 1 & 2 & 1 & 1 & 2\end{array}$

$\begin{array}{lllllllll}1 & 1 & 1 & 2 & 1 & 2 & 2 & 2 & 2\end{array}$

$2 \div \quad \mathrm{B} 2 \mathrm{C}$

A B CDEFGH I $\begin{array}{lllllllll}1 & 0 & 2 & 0 & 2 & 1 & 1 & 0 & 0\end{array}$ $\begin{array}{lllllllll}2 & 1 & 1 & 2 & 2 & 1 & 2 & 1 & 0\end{array}$

$\begin{array}{lllllllll}0 & 2 & 0 & 1 & 2 & 1 & 0 & 2 & 0\end{array}$

$\begin{array}{lllllllll}1 & 0 & 2 & 1 & 1 & 0 & 2 & 0 & 1\end{array}$

$\begin{array}{lllllllll}2 & 1 & 1 & 0 & 1 & 0 & 0 & 1 & 1\end{array}$

$\begin{array}{lllllllll}0 & 2 & 0 & 2 & 1 & 0 & 1 & 2 & 1\end{array}$

$\begin{array}{lllllllll}1 & 0 & 2 & 2 & 0 & 2 & 0 & 0 & 2\end{array}$

$\begin{array}{lllllllll}2 & 1 & 1 & 1 & 0 & 2 & 1 & 1 & 2\end{array}$

$\begin{array}{lllllllll}0 & 2 & 0 & 0 & 0 & 2 & 2 & 2 & 2\end{array}$ 


\section{EXAMPLE (3)}

Reference: (6), Table 1, p. 58

Experiment: Plan which permits estimation of all maineffects and all two-factor interactions containing $A$ for a $4^{6}$.

Number of Experimental Points: 64

Computer: UNIVAC 1107

Time Required: 1.90 seconds - essentially the time required for a $2^{12}$.

Restrictions: $\mathrm{B}+\mathrm{C}=\mathrm{D}, \mathrm{B}+" 2 " \mathrm{C}=\mathrm{E}, \mathrm{B}+" \mathrm{~B}^{\prime \prime} \mathrm{C}=\mathrm{F}$ or

$\mathrm{B}+\mathrm{C}+\mathrm{D}=0, \mathrm{~B}+\mathrm{xC}+\mathrm{E}=0$,

$B+(x+1) C+F=0$

$\begin{array}{cl}\text { Four Level } & \frac{\text { Two Level }}{u_{2}+u_{3}+u_{4}=0} \\ u_{2}+u_{3}+u_{5}=0 & C+E+G=0 \\ u_{2}+(x+1) u_{3}+u_{6}=0 & C+E+F+I=0 \\ & D+E+J=0 \\ & C+F+K=0 \\ & D+E+F+L=0\end{array}$

Comments: The arithmetic operations of the Galois Field $\left(2^{2}\right)$ must be used in all manipulations. There is a temptation to write the second restriction as $(B+C)+C=D+C=E$. However, under the permissible operations $1 \cdot \mathrm{C}+1 \cdot \mathrm{C}=(1+1) \mathrm{C}=$ $0 \cdot C=0$, and the net result is that the maineffects $B$ and $E$ are totally confounded if the above is done.

Computer Output:

\section{IC VHRIAELES ORESTRLCTLUNS}

\begin{tabular}{|c|c|c|c|c|c|c|c|c|c|c|c|}
\hline & A & $b$ & $c$ & 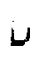 & $E$ & $F$ & 0 & $\mathrm{r}$ & 1 & 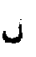 & \\
\hline u & v & $v$ & 1 & 0 & 1 & u & 1 & 0 & U & 0 & U \\
\hline 0 & 0 & 0 & 0 & 1 & 0 & 1 & 0 & 1 & U & 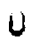 & 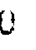 \\
\hline 0 & U & $\iota$ & 1 & 0 & 1 & 1 & $U$ & 0 & 1 & 0 & u \\
\hline 4 & 0 & $\mathrm{~b}$ & L & 1 & 1 & u & $t^{2}$ & 0 & 0 & 1 & 4 \\
\hline 4 & 0 & $v$ & $I$ & 0 & 0 & 1 & ن & $u$ & $u$ & 0 & 1 \\
\hline & $\tilde{u}$ & $v$ & v & 1 & 1 & 1 & u & $u$ & U & U & 4 \\
\hline
\end{tabular}




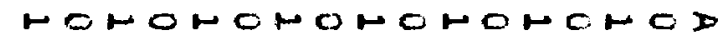

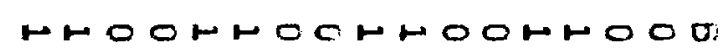

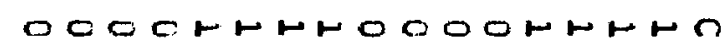

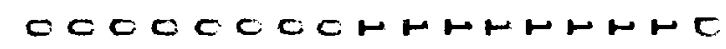
$0000000000000000 \mathrm{~m}$

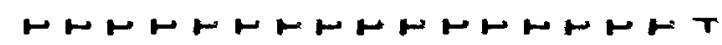
CCCOトम

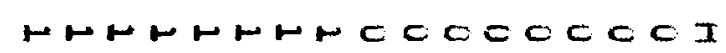

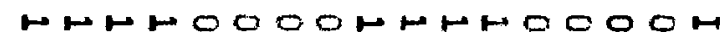

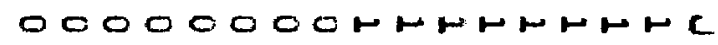

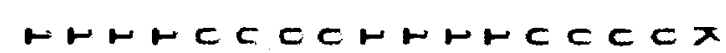

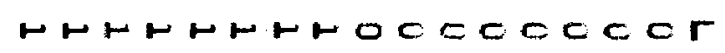

HCHOWOHOHCHCHOMOI

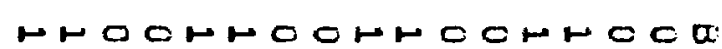

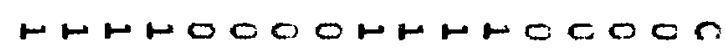

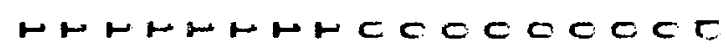
$0000000000000000 \mathrm{~m}$ COCCCECCOCCECCCT

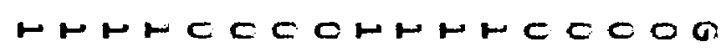

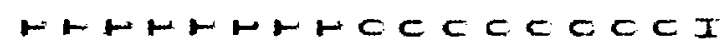

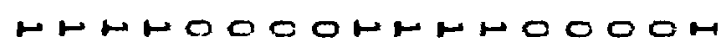

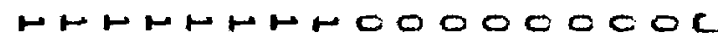
HrH

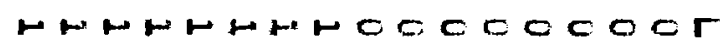


WOHCHOHOHOHOWOHCI -

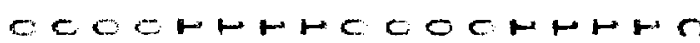

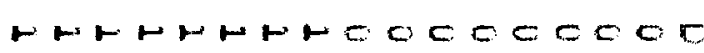

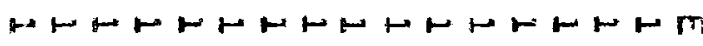

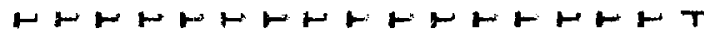

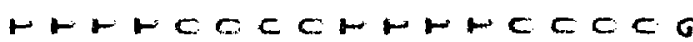

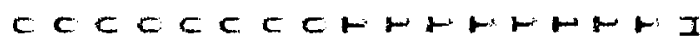
OODOஈ

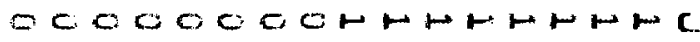
H WHWHWHCECCECC

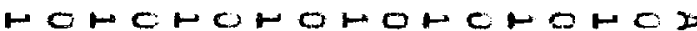
以 Hஈ CCCOCECOHHMHMHHHC

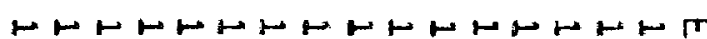
CECCCCECCECCCCCCT OCCONWWHOCOHWH,

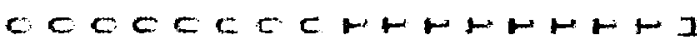

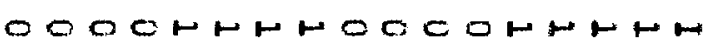
WHWHWHWCOCOCOCOC HMRCCOCH M MCCCCX H 

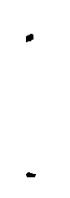
APPENDIX E 


\title{
APPENDIX E
}

The following is a listing of the Fortran IV main program for the $2^{\mathrm{m}}$ series calculation, which is nearly the same for the IBM 7090 and UNIVAC 1107 computers (tive 1107 requires the CALL SETIO statements found near the bottom of this page):

$c$
$c$
$c$
$c$
$c$
$c$
$c$
$c$
$C$
$C$
$c$
$C$
$C$
$C$
$C$
$C$

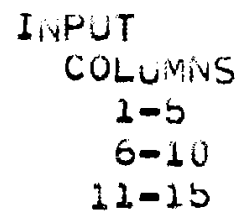
$12-15$

BOT Cren 25

\author{
MDANUNBCH OF
}

THEA WR CARUS CONTAINING I OR U LI EACH OF PIRST 35 CULUMAS COLUMN SO CUNTAINS O IF EVEN PAKITY SHOULU CAUSE SELECTION 1 IF OLL PAKITY SHOULL CAUSE SELECTION

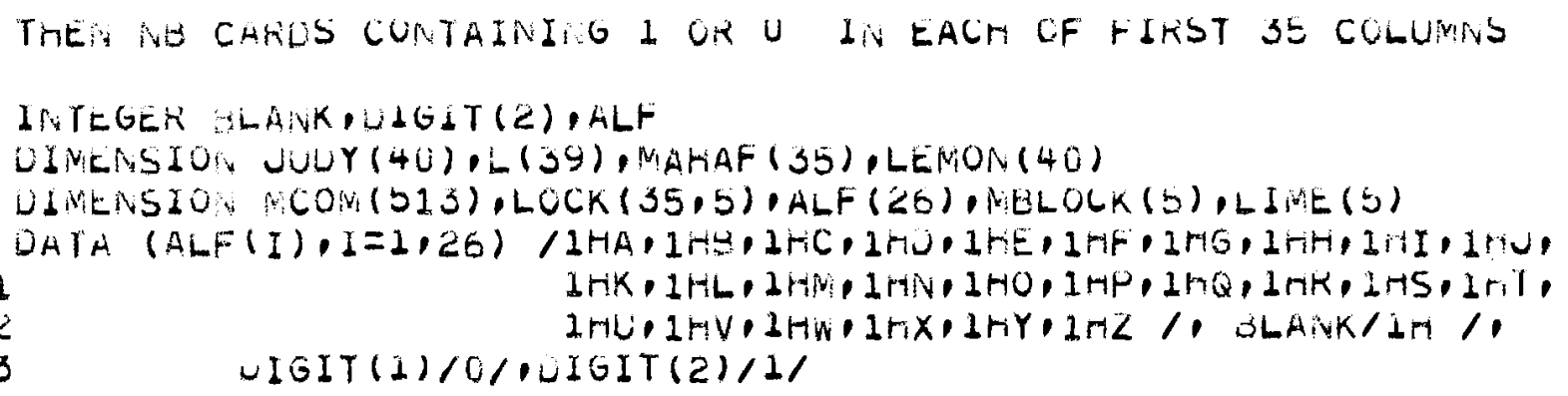

900 FOKIMAT (3I5)

910 FURMAT $(3511.14 X 11)$

920 FOKMATI IMII35,I2H VARIABLES I1U.1SH KESTKICT1CHS //1)

929 FORIAT $(41 \times 25(1 \times A) /$ Lh $)$

930 FOKAAT $(31 \times I 5,5 \times 3512)$

950 FORAAT( IHOI35,21M EXPERIMENTAL POINTS /1H)

951 FOKMATISSHOMORE THAIV 322 EXPEKLMENTHL POINTS /1M)

$96 U$ FORVAT $(1 \times 3913)$

970 FORMAT(INU20X18HTIME REQUIRED WAS F7.3, 9H SECUNOS.)

981 FORAAT (1:0 I2, $3 H=25(1 \times A 1))$

982 FORIMTIIHO 1OX [2,SH $=23(1 \times A 1))$

983 FURIAT(1riU $20 X \quad 12,3 H=20(1 \times A 1))$

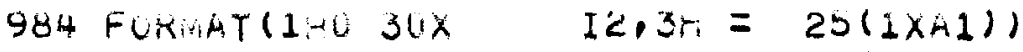

985 FURWAT(1WU $40 X$ I2.SH $=25(1 \times A 1))$

990 FCRRATIIHU OSX $25(1 \times A D) / D H$ )

991 FORIATL OOX 25L2)

CALL SETIE $(3,2)$

- Call Setio $(2,1)$

IU CONTINUE

CALL ETI IE

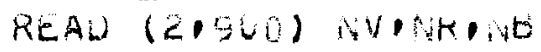




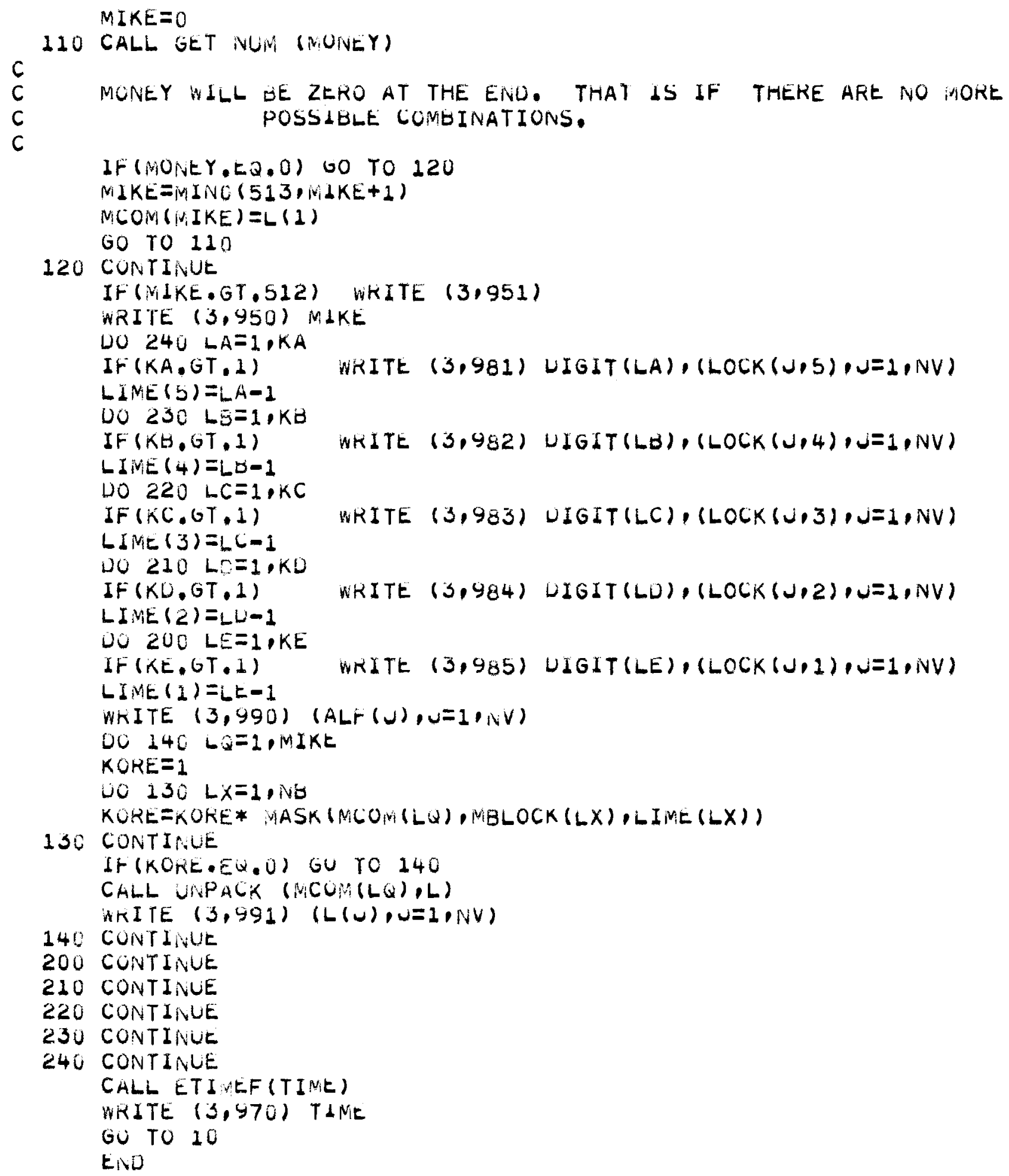


The following subroutine was written in MAP language for the IBM 7090 for tile $2^{m}$ series:

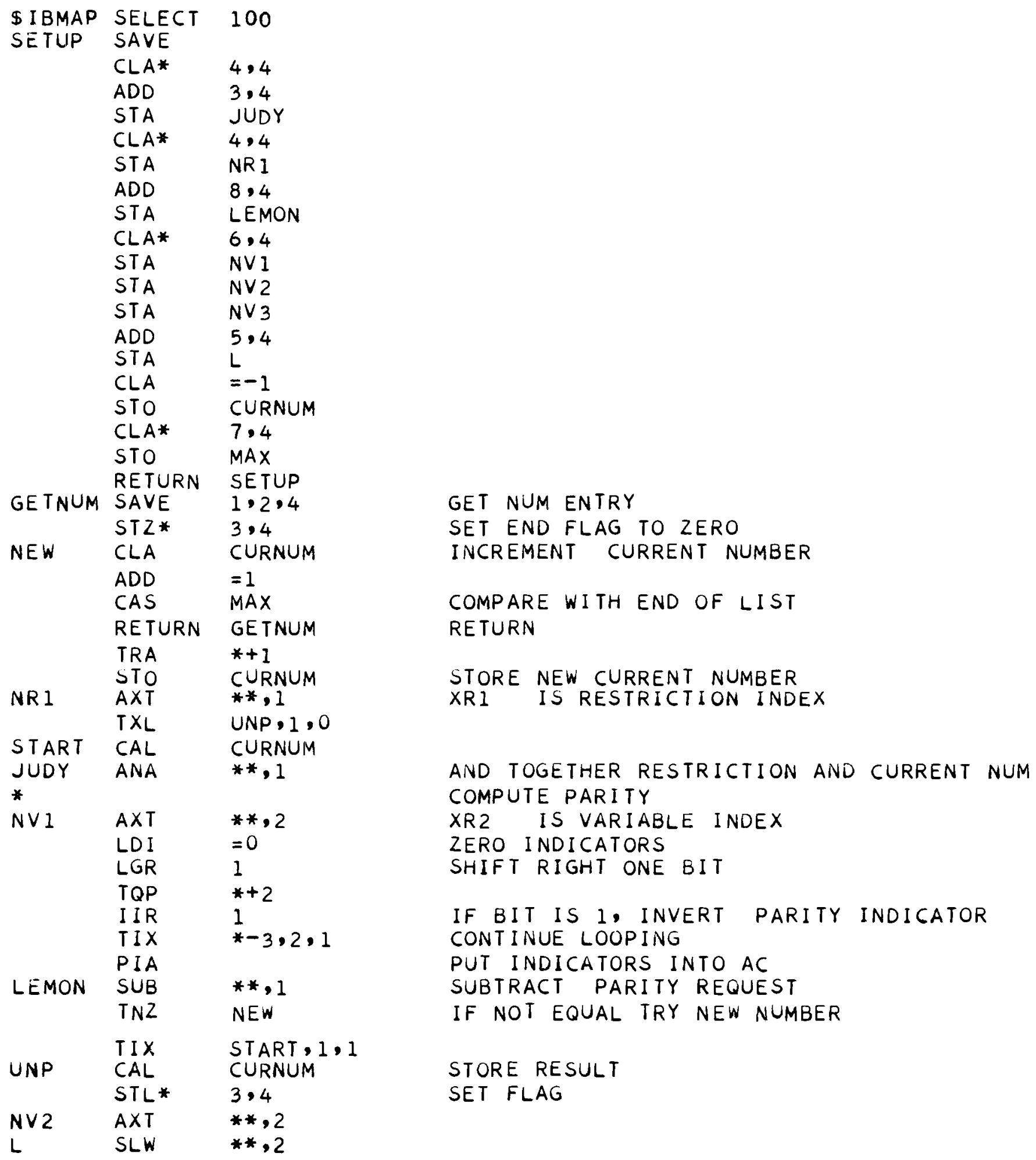




$\begin{array}{lll} & \text { RETURN } & \text { GETNUM } \\ \text { CURNUM } & \text { PZE } & \\ \text { MAX } & \text { PZE } & \\ \text { UNPACK } & \text { SAVE } & 2 \\ & \text { CLA } & 4,4 \\ & \text { ADD } & =25 \\ & \text { STA } & \text { LL } \\ \text { CAL* } & 3,4 \\ & \text { AXT } & 25,2 \\ & \text { LDQ } & =0 \\ & \text { LGR } & 1 \\ & \text { RQL } & 1 \\ & \text { STQ } & * *, 2 \\ \text { LL } & \text { TIX } & *-4,2,1 \\ & \text { RETURN } & \text { UNPACK } \\ \text { MASK } & \text { SAVE } & 2 \\ & \text { CAL* } & 3,4 \\ & \text { ANA* } & 4,4 \\ \text { NV3 } & \text { AXT } & * *, 2 \\ & \text { LDI } & =0 \\ & \text { LGR } & 1 \\ & \text { TQP } & *+2 \\ & \text { IIR } & 1 \\ & \text { TIX } & *-3,2,1 \\ & \text { PIA } & \\ & \text { SUB* } & 5,4 \\ & \text { COM } & \\ & \text { ANA } & =1 \\ & \text { RETURN } & \text { MASK } \\ & \text { END } & \\ & & \end{array}$

UNPACK NUMBER

AND TOGETHER FIRST TWO ARGUMENTS COMPUTE RESULTING PARITY.

IF PARITY IS EQUAL TO THIRD ARGUMENT RETURN 1. OTHERWISE RETURN ZERO.

The following subroutine was written in Sleuth II language for the UNIVAC 1107 for the $2^{\mathrm{m}}$ series:
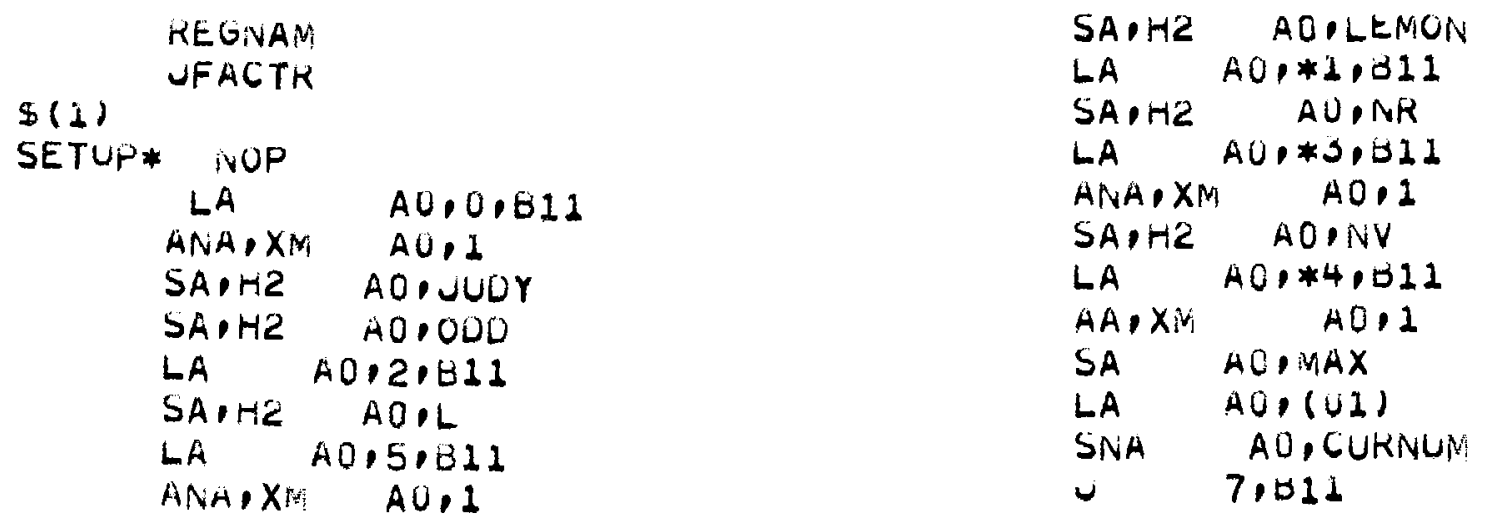

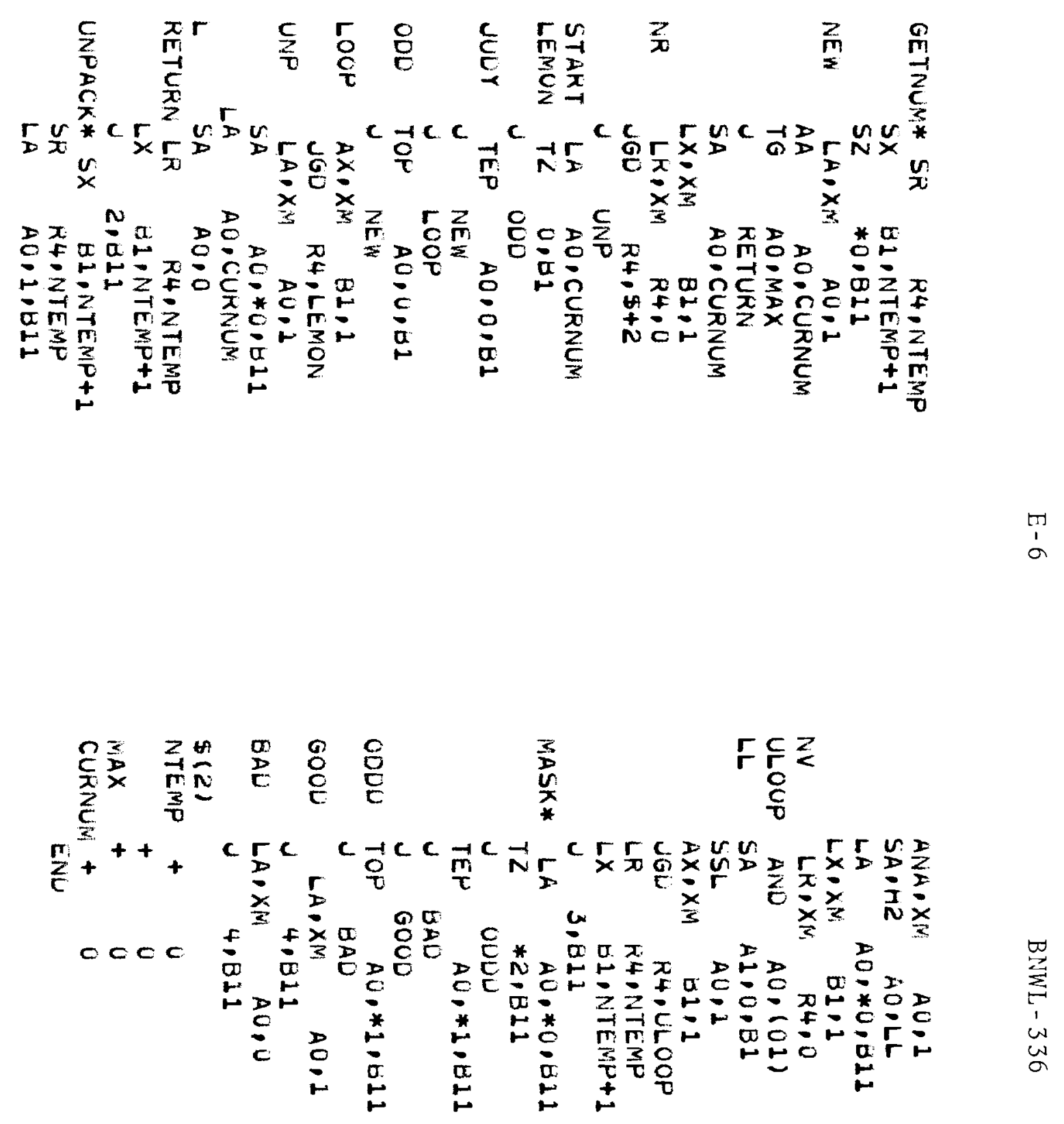
The following is a listing of the Fortran IV main program for the $3^{\text {n }}$ series calculation for the IBM 7090 computer:

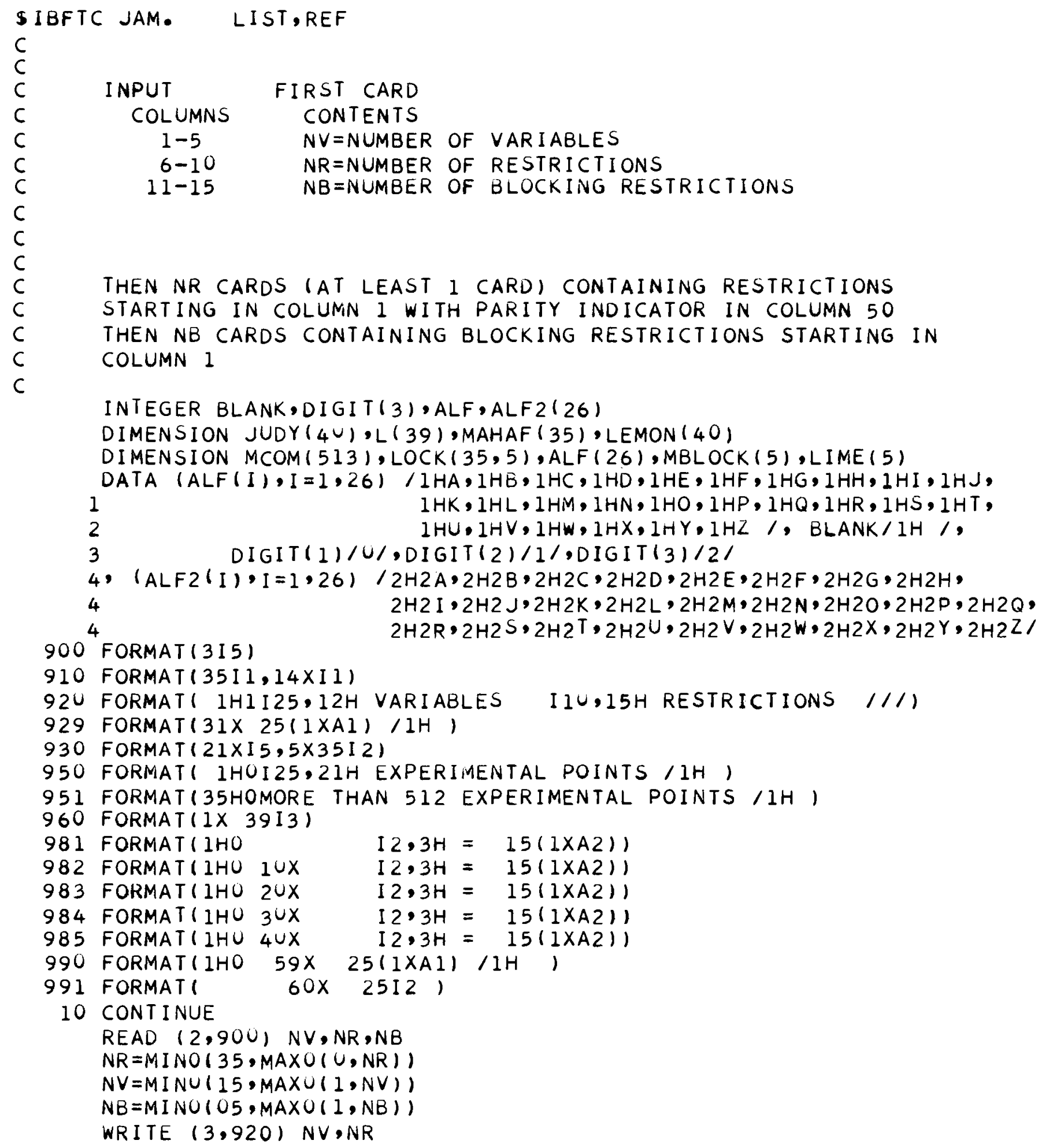

THEN NR CARDS (AT LEAST I CARD) CONTAINING RESTRICTIONS START ING IN COLUMN I WITH PARITY INDICATOR IN COLUMN 50 THEN NB CARDS CONTAINING BLOCKING RESTRICTIONS STARTING IN COLUMN 1

INTEGER BLANK, DIGIT(3), ALF, ALF2 (26)

DIMENSION JUDY (4U), L (39), MAHAF (35), LEMON (40)

DIMENSION MCOM( 513$), \operatorname{LOCK}(35,5), A L F(26), M B L O C K(5), \operatorname{LIME}(5)$

DATA (ALF (I),I = I,26) / IHA, IHE, IHC, 1HD, IHE, IHF, IHG, IHH, IHI, IHJ, 1

2 $1 H K, 1 H L, 1 H M, 1 H N, 1 H O, I H P, 1 H Q, 1 H R, 1 H S, 1 H T$, $1 H U, 1 H V, I H W, 1 H X, 1 H Y, 1 H Z /, B L A N K / 1 H /$,

4, (ALF2(I), I =1,26) / $2 \mathrm{H} 2 \mathrm{~A}, 2 \mathrm{H} 2 \mathrm{~B}, 2 \mathrm{H} 2 \mathrm{C}, 2 \mathrm{H} 2 \mathrm{D}, 2 \mathrm{H} 2 \mathrm{E}, 2 \mathrm{H} 2 \mathrm{~F}, 2 \mathrm{H} 2 \mathrm{G}, 2 \mathrm{H} 2 \mathrm{H}$, 4 $2 \mathrm{H} 2 \mathrm{I}, 2 \mathrm{H} 2 \mathrm{~J}, 2 \mathrm{H} 2 \mathrm{~K}, 2 \mathrm{H} 2 \mathrm{~L}, 2 \mathrm{H} 2 \mathrm{M}, 2 \mathrm{H} 2 \mathrm{~N}, 2 \mathrm{H} 2 \mathrm{O}, 2 \mathrm{H} 2 \mathrm{P}, 2 \mathrm{H} 2 \mathrm{Q}$, 4

900 FORMAT (3I5) $2 \mathrm{H} 2 \mathrm{R}, 2 \mathrm{H} 2 \mathrm{~S}, 2 \mathrm{H} 2 \mathrm{~T}, 2 \mathrm{H} 2 \mathrm{U}, 2 \mathrm{H} 2 \mathrm{~V}, 2 \mathrm{H} 2 \mathrm{~W}, 2 \mathrm{H} 2 \mathrm{X}, 2 \mathrm{H} 2 \mathrm{Y}, 2 \mathrm{H} 2 \mathrm{Zl}$

910 FORMAT (35I1,14XI1)

920 FORMATI IHII25,12H VARIABLES IIU,15H RESTRICTIONS ///)

929 FORMAT $(31 \times 25(1 \times A) / 1 H)$

930 FORMAT $(21 \times 15,5 \times 3512)$

950 FORMAT( IHOI25,21H EXPERIMENTAL POINTS / IH )

951 FORMAT (35HOMORE THAN 512 EXPERIMENTAL POINTS /IH )

960 FORMAT $(1 \times 39$ I3)

981 FORMAT (1HO I2,3H $=15(1 \times A 2))$

982 FORMAT(IHU IUX I, $3 \mathrm{H}=15(1 \times A 2))$

983 FORMAT(IHO $2 \cup X \quad I 2,3 \mathrm{H}=15(1 \times A 2))$

984 FORMAT(IHU 3UX $\quad 12,3 \mathrm{H}=15(1 \times A 2))$

985 FORMAT(IHU 4UX I $33 \mathrm{H}=15(1 \times A 2))$

990 FORMAT( $1 H 0$ 59X $25(1 \times A 1) / 1 H)$

991 FORMAT( 60X $25 I 2$ )

10 CONT INUE

READ (2,900) NV,NR,NB $N R=M I N O(35, M A X O(U, N R))$ $N V=M I N U(15, M A X U(1, N V))$ $N B=M I N O(05, M A X O(1, N B))$ WRITE $(3,920) \quad N V, N R$ 


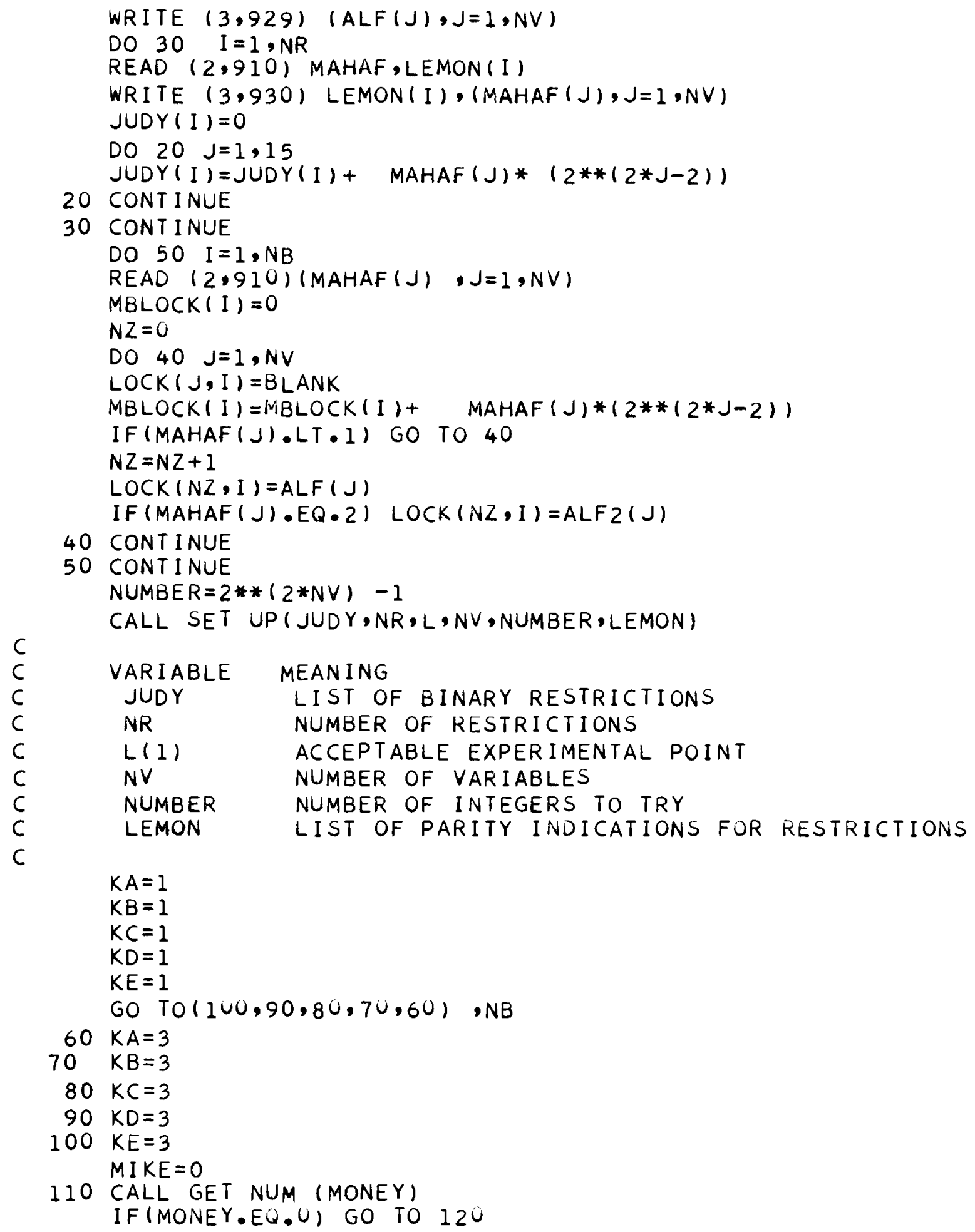




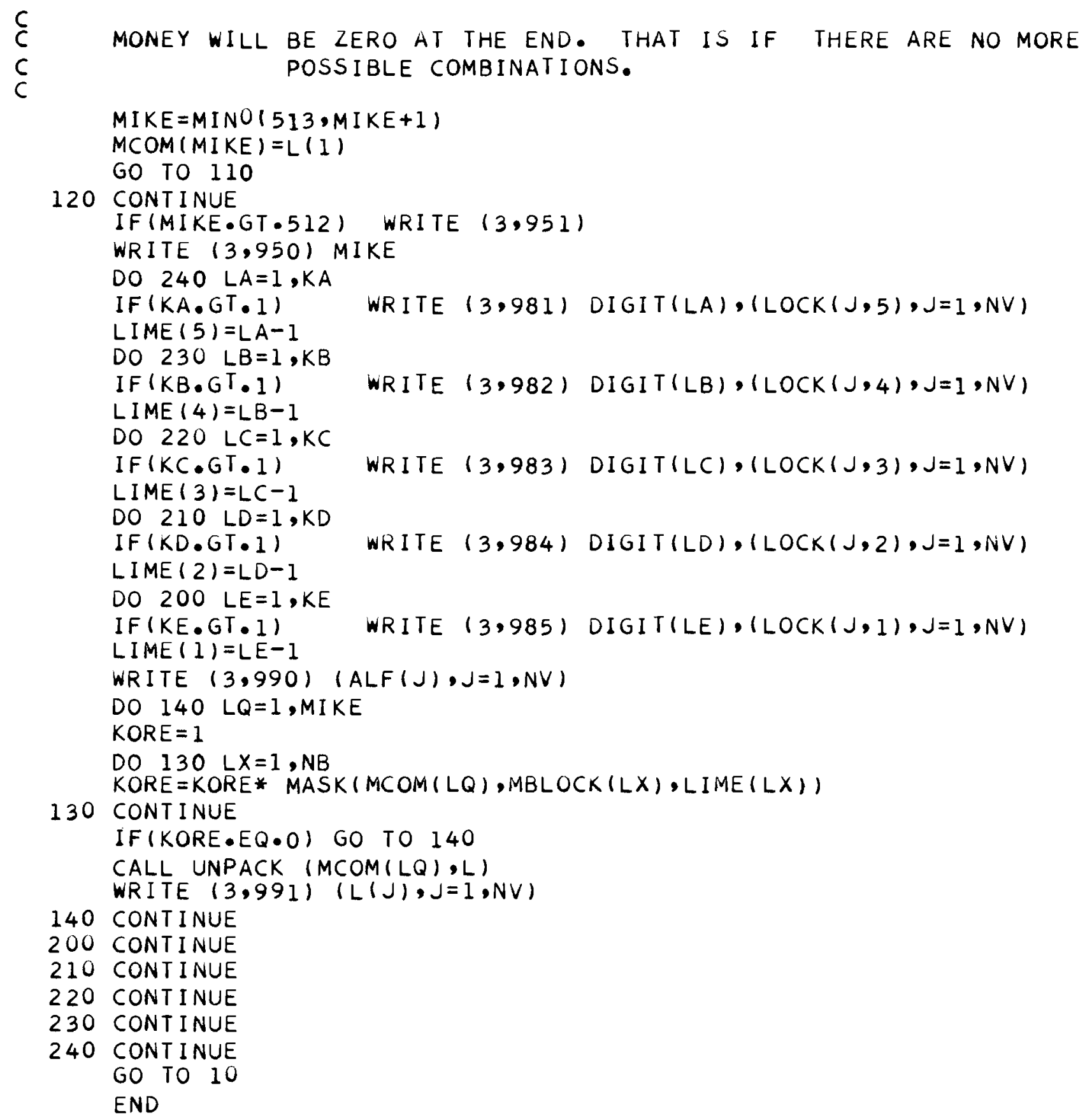


The following subroutine was written in MAP language for tine IBM 7090 for the $3^{\text {n }}$ series:

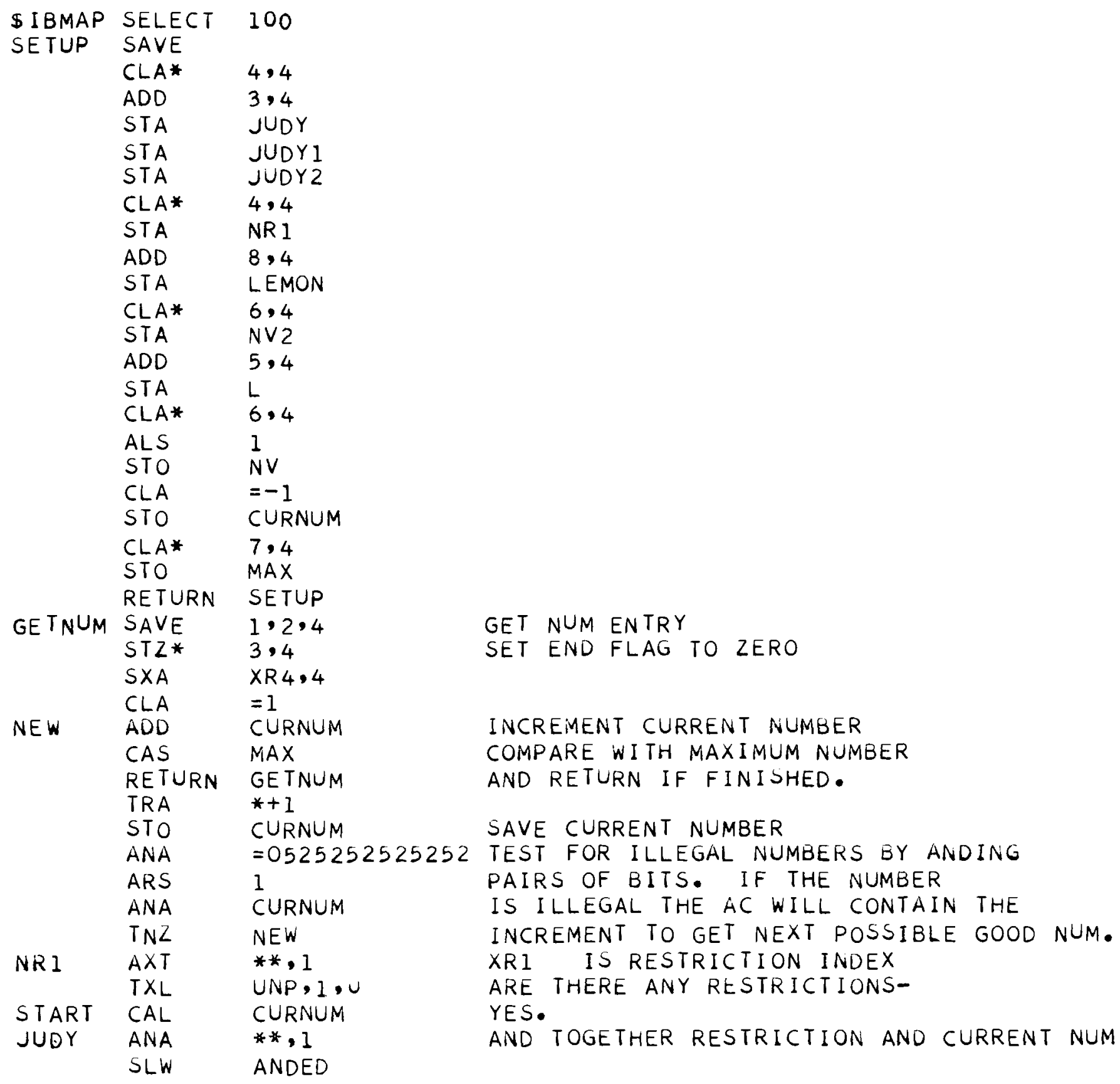




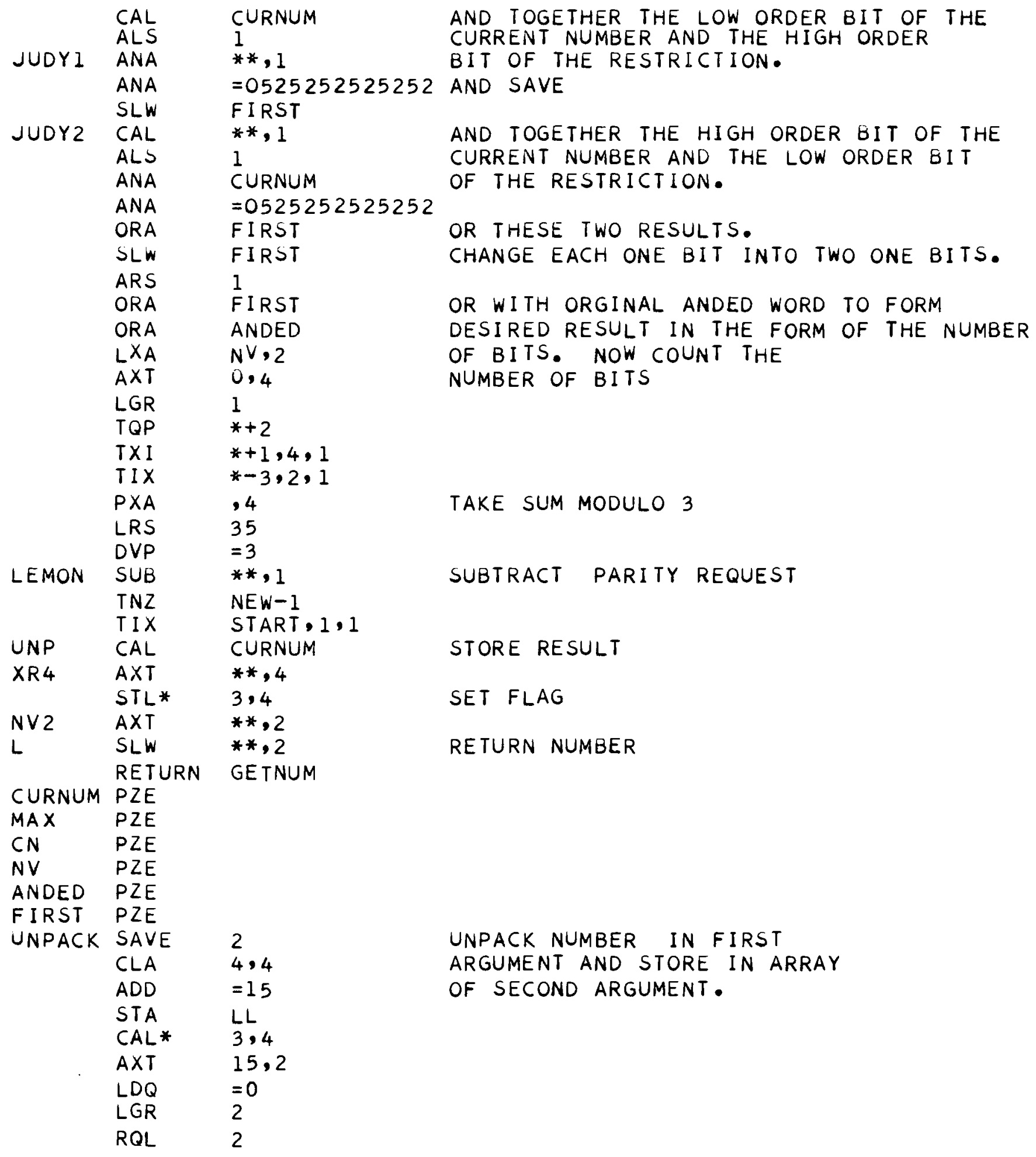




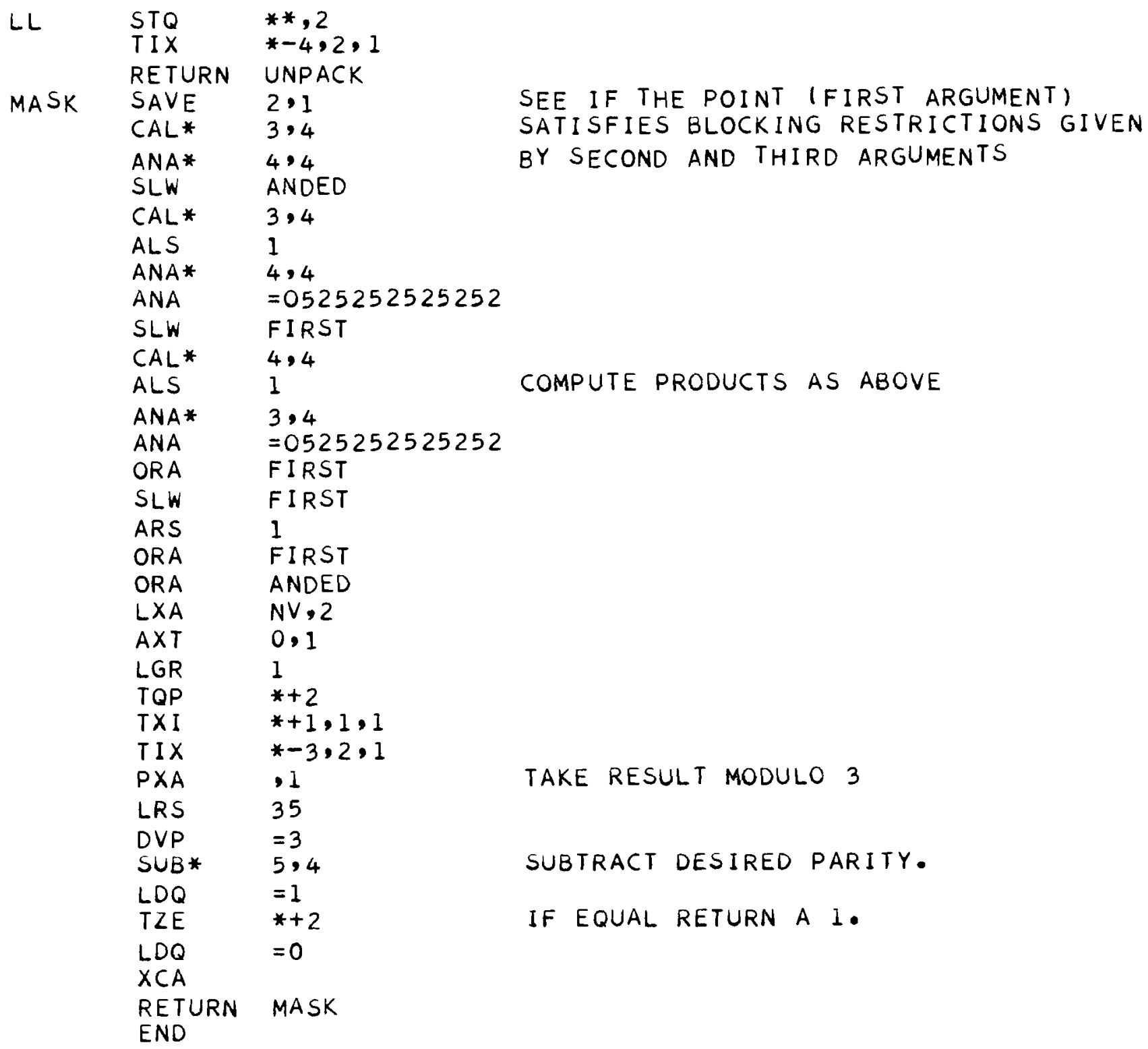

SEE IF THE POINT (FIRST ARGUMENT) SATISFIES BLOCKING RESTRICTIONS GIVEN

TAKE RESULT MODULO 3

SUBTRACT DESIRED PARITY.

IF EQUAL RETURN A 1. 


\section{DISTRIBUTION}

Number

of Copies

293 AEC Division of Technical

2 AEC Richland Operations Office

R. K. Sharp

Technical Information

Library

$1 \quad$ American Cyanamid Company

Berdan Avenue

Wayne, New York 07470

Otto Dykstra

$1 \quad$ American Oil Company

2700 New York Avenue

Whiting, Indiana 46394

John W. Gorman

1 Argonne National Laboratory 9700 South Cass Avenue Argonne, Illino is 60439

Richard F. King

$1 \quad$ Arizona State University

7035 N. 69th P1ace

Scottsdale, Arizona 85251

John E. Freund

1 Be11 Telephone Laboratory Murray Hil1, New Jersey 07971

Martin B. Wilk

3 Boeing Scientific Research Labs Box 3981

Seattle, Washington 98124

James D. Esary

Frank Prochan

Sam C. Saunders

1 Brigham Young University

Provo, Utah 84601

Dale 0 . Richards

1 Buckne11 University

Lewisburg, Pa. 17837

Chairman, Dept. of Math

1 Bureau of Ships

18 th and Constitution Avenue

Washington, D.C.

Beatrice S. Orleans

1 Brookhaven National Laboratory Upton, New York 11719
Number

of Copies

1 Carnegie Institute of Technology Frewe Avenue and Margaret Morrison Street, Pittsburgh, Pennsylvania 15213

Chairman, Dept. of Math

1 Case Institute of Technology 10900 Euclid Avenue Cleveland, Ohio 44106

Chairman, Dept. of Math

1 Colorado State University Fort Collins, Colorado 80521

Franklin A. Graybil1

1 Columbia University Broadway and West 116 th New York, New York 10027

Chairman, Dept. of Math

2 Cornel1 University

Ithaca, New York 14850

Walter T. Federer

Robert Beckhofer

1 Dartmouth College

Hanover, New Hampshire 03755

Thomas E. Kurtz

1 Dugway Field Office

C.E.I.R., Inc.

Box 241

Dugway, Utan 84022

Floyd I. John

1 E. I. DuPont de Nemours \& Co., Inc.

Louviers Building

Newark, Delaware 19711

Donald W. Marquardt

1 Florida State University Tallahassee, Florida 32306

Ralph A. Bradley

1 Genera1 Electric Company

Appliance Park

Lou isville, Kentucky 40225

Ernest Bianco

1 General Foods

White Plains, New York

Mavis Carol 
Number of Copies

1 General Tire and Rubber Company 1708 Englewood Avenue Akron, Ohio 44309

Alonzo Church, Jr.

1 The George Washington University Washington D.C. 20006

Solomon Kul1back

$1 \quad$ Harvard University Room 311, 2 Divinity Avenue Cambridge, Massachusetts 02138

Frederick Moste11er

1 Iowa State University of Science and Technology Ames, Iowa 50010

T. A. Bancroft

1 Johns Hopkins University 615 Nortin Wolfe Street Baltimore, Maryland 21205

Allyn W. Kimba11, Jr.

1 Kansas State University Manhattan, Kansas 66504

H. C. Fryer

1 Knolls Atomic Power Laboratory River Road

Schenectady, New York 12301

Glen Burrows

1 Michigan State University East Lansing, Michigan 48823

Leo Katz

1 Montana State University Bozeman, Montana 59715

Charles Quesenberry

1 National Bureau of Standards Boulder, Colorado 80301

Edwin L. Crow

1 National Bureau of Standards Washington, D.C. 20234

Joseph $M$. Cameron

1 National Institute of Health U.S. Public Health Service Bethesda, Maryland 20014

Jerome Cornfield

1 Naval Post Graduate Schoo1 Monterey, California 93940

Jack R. Borsting
Number

of Copies

1 New York University

25 Waverly Place

New York, New York 10003

A1 1 an Birnbaum

1 North Carolina State

Box 5457

Raleigh, North Carolina 27607

Robert J. Hader

1 Oak Ridge National Laboratory

P.O. Box Y

Oak Ridge, Tennessee 37831

Marvin A. Kastenbaum

2 Ohio State University

N. High

Columbus, Ohio 43210

H. F. Mathis

D. Ransom

1 Oklahoma State University

Stil1water, oklahoma 74074

John L. Folks

1 Oregon State University

240 Extension Hall

Corvallis, Oregon 97330

Lyle D. Calvin

2 Princeton University

Princeton, New Jersey 08540

$\mathrm{J}$. Stuart lunter

John W. Tukey

1 Proctor and Gamble

Ivorydale Technical Center

Cincinnati, Ohio 45217

John Comer

1 Purdue University

Lafayette, Indiana 47907

Virgil L. Anderson

2 Rensselaer Polytechnic Institute Troy, New York 12180

I rving Burr

John W. Wilkinson

1 Research Triangle Institute Box 490

Durham, North Carolina 27702

A. L. Finkner

1 Rocketdyne (a Div. of N. American Aviation)

$\overline{6} 63 \overline{3}$ Canoga Avenue

Canoga Park, California 91303

Steve Webb 
Number of Copies

1 Rutgers - The State University New Brunswick, New Jersey $0 \overline{8903}$

H. P. And rews

1 Sandia Corporation Albuquerque, New Mexico 87115

George P. Steck

1 Southern Methodist University Dallas, Texas 75222

Paul D. Minton

1 Standard Oil Company (Ohio) 4440 Warrensville Center Road Cleveland, Ohio 44128

Richard J. De Gray

1 Stanford Research Institute Menlo Park, California 94025

William G. Madow

2 Stanford University

Stanford, California 94305

Gerald J. Lieberman

Lincoln E. Moses

1 State University of New York at Buffalo

Buffalo, New York 14214

Norman C. Severo

1 Texas A \& $M$

College Station, Texas 77843

H. o. Hartley

1 Union Carbide Chemical Division Box 8361, South Charleston, West Virginia

Ben H. Carpenter

1 University of Arizona Tucson, Arizona 85721

Henry Tucker

1 University of Chicago

$\overline{1} 118$ East $58 \mathrm{th}$ Street

Chicago, Illinois 60637

Paul Meier

2 University of California

Berkeley, California 94720

Henry Scheffe

Alvin D. Wiggins
Number

of Copies

2 University of California (UCLA) Los Angeles, California 90024

Wilfrid J. Dixon

Paul G. Hoel

1 University of Colorado Boulder, Colorado 80302

Thornton C. Fry

1 University of Florida Gainesville, Florida 32601

Wm. E. Mendenha 11

1 University of Georgia

Athens, Georgia 30601

Carl F. Kossack

1 University of Illinois

Urbana, Illinois 61801

Colin R. Blyth

1 University of Iowa

Iowa City, Iowa 52240

Fred C. Leone

1 The University of Kansas

Lawrence, Kansas 66044

Russel1 N. Bradt

1 University of Michigan

Ann Arbor, Michigan 48104

C. C. Craig

2 University of Minnesota

Minneapolis, Minnesota 55455

$\mathrm{Jacob}$ E. Bearman

B. W. Lindgren

1 University of Missouri

Columbia, Missouri 65201

Chairman, Dept. of Statistics

1 University of Montana

Missoula, Montana 59801

Howard Reinhardt

1 University of Nebraska

Lincoln, Nebraska 68508

Bernard Harris

1 University of New Mexico

Albuquerque, New Mexico 87106

Julius R. Bl um 
Number of Copies

1

University of North Carolina Chapel Hill, North Carolina 27515

George E. Nicholson, Jr.

1 University of North Dakota Grand Forks, North Dakota 58201

Milton E. Winger

1 University of Oklahoma Medical Center 800 N.E. 13th street

Oklahoma City, Oklahoma 73104

Edward N. Brandt, Jr.

11 University of Oregon Eugene, Oregon 97403

Fred C. Andrews (1)

John Reinmuth (10)

1 University of Oregon Dental School 611 S.W. Campus Drive Portland, Oregon 97201

Kuo Hwa Lu

1 University of Utah 1400 East 2nd Street Salt Lake City, Utah 84112

2 University of Washington 15 th Avenue, NE and NE 40 th Seattle, Washington 98105

Z. W. Birnbaum

D. P. Chapman

1 University of Wisconsin 710 University Avenue Madison, Wisconsin 53715

George E. P. Box

1 University of Wisconsin Sterling Hall

Madison, Wisconsin 53706

Mervin E. Muller

1 University of Wyoming Laramie, Wyoming 82071

William C. Guenther

1 U.S. Army Electronics R\&D Lab Fort Monmouth, New Jersey 07703

Joseph Weinstein
Number of Copies

1 Utah State University Logan, Utah 84321 Rex L. Hurst

1 Virginia Polytechnic Institute Blacksburg, Virginia 24061

Boyd Harshbarger

3 Washington State University Pullman, Washington 99163

kenneth A. Bush

Paul L. Meyer

Thomas S. Russe11

1 Westinghouse Research and Development Center Beulah Road

Pittsburgh, Pennsylvania 15235

Robert Hooke

1 Wright-Patterson Air Force Base ohio 45433

II. Leon Harter

$1 \quad$ Yale University

Box 2179

Yale Station

New Haven, Connecticut 06520

Francis J. Anscombe

Battelle-Northwest

T. M. Beetle

C. A. Bennett

R. L. Buschbom

G. M. Dalen

R. Y. Dean

E. A. Eschbach

R. L. Hooper

C. G. llough

J. L. Jaech

A. Kraft

J. A. Mahaffey (10)

W. L. Nicholson

C. H. Oster

J. E. Schlosser (10)

J. M. Thomas

P. Tucker

B. B. Vinson

J. A. Weed

R. S. Wilhe $1 \mathrm{~m}$

Technical Information Files

Technical Publications (1) 